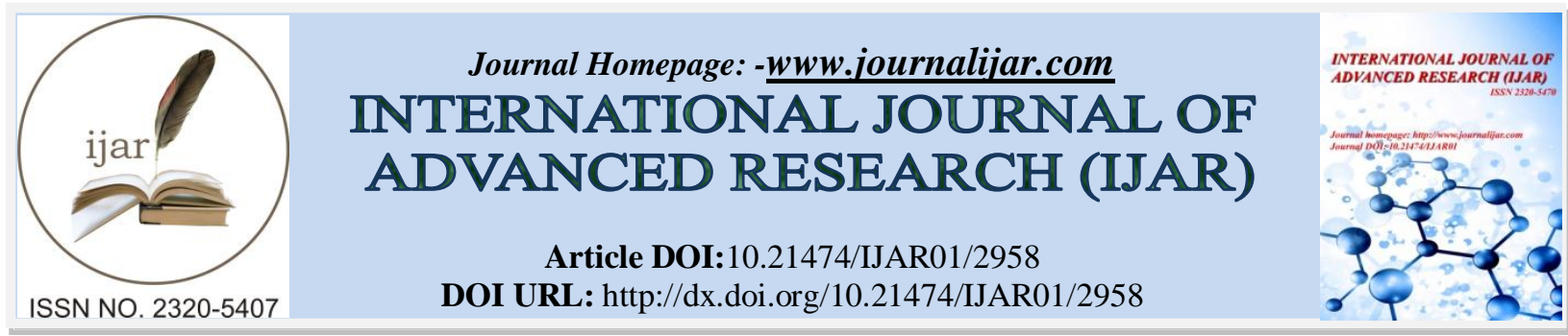

RESEARCH ARTICLE

\title{
PROGNOSTIC AND PREDICTIVE SIGNIFICANCE OF PROGRAMMED DEATH LIGAND (PD-L1) AND FOXP3 EXPRESSIONS IN TUMOR CELLS AND TUMOR MICROENVIRONMENT IN OVARIAN CANCER PATIENTS
}

\section{Lobna A. Abdelaziz ${ }^{1}$, Shereen El Shorbagy ${ }^{2}$, Ola M Elfarargy ${ }^{2}$, Ola A. Harb $^{3}$, and Abeer M Abdelbary ${ }^{3}$.}

1. Clinical Oncology and Nuclear Medicine Department, Faculty of Medicine, Zagazig University.

2. Medical Oncology Department, Faculty of Medicine, Zagazig University.

3. Pathology Department, Faculty of Medicine, Zagazig University.

\section{Manuscript Info}

(1.........................

Manuscript History

Received: 29 November 2016

Final Accepted: 26 December 2016

Published: January 2017

Key words:-

Epithelial ovarian cancer, microenvironment; PD-L1; FOXP3; prognosis

\section{Abstract}

Background: The microenvironment of epithelial ovarian cancer (EOC) continued to be an important point of research to discover new therapeutic targets for such malignancy. It was discovered that any cells that were in the microenvironment of the EOC may be associated with cancer prognosis like tumor-infiltrating lymphocytes (TILs) and Tregulatory cells (Tregs).

The PD-1/PD-L1 pathway was a T-cell checkpoint pathway that sent inhibitory signals to $\mathrm{T}$ cells that can inhibit immunity. PDL1, a PD-1 ligand, is detected in lymphocytes, dendritic cells, macrophages and tumor cells. Tregs (mature T lymphocytes) that start in the thymus after stimulation of naïve $T$ cells and responsible for the reduction of autoimmune diseases, but its over production will inhibit endogenous protection against infection and tumors. Forkhead/winged-helix transcription factor box P3 (Foxp3) is an intracellular molecule for Tregs growth and maturation and was found to be the most specific Tregs marker. It was found that Foxp3 is not only found in Treg cells that originated in the thymus but also in malignant cells and its difference in expression can affect the outcome of cancer patients.

Aim of our study: was to assess PD-L1 and FOXP3 expression in epithelial ovarian carcinoma a trial to detect their prognostic value and their impact on survival in patients with such type of cancer.

Methods: The expressions of PD-L1 and FOXP3 in both tumor cells and stromawere evaluated in sections of 50 paraffin blocks that were retrieved from 50 patients with EOC using immunohistochemistry.We assessed the relation between their expressions, clinicopathological parameters, survival and prognosis of those patients

Results: Expression of PDL-1 in tumor cellswas positively correlated with; grade, stage of the tumor, LN metastasis $(\mathrm{p}=0.001)$ and histopathological type (0.011), type of surgery and residual disease after surgery $(\mathrm{P}=0.010)$.Expression of PDL-1 in TILswas positively correlated with grade $(p=0.033)$ and stage of the tumor $(p=0.029)$.

Expression of FOXP3in tumor cellswas positively correlated with; age of the patients $(\mathrm{p}=0.017)$, grade $(\mathrm{p}=0.010)$, stage of the tumor $(\mathrm{p}<0.001)$ and distant metastases $(\mathrm{p}=0.002)$. Whereas the expression of 
FOXP3in TILs was correlated with histological type $(\mathrm{P}=0.038)$. Combined low PDL1\& FOXP3 expressions in tumor cells were significantly associated withhigher progression free survival (PFS) $(\mathrm{p}<0.045)$.

There were highly significant statistical relations were found between expression of each marker in tumor cells and Pdl1 in TILs and both Pdl1 \&FOXP3 in TILs ( $\mathrm{p}<0.001)$.

There were highly significant statistical relations between expression of both markers in TILs and each one of the following ( Pdl1 in tumor cells $(\mathrm{P}<0.001)$, FOXP3 expression in tumor cells $(\mathrm{p}=0.007)$ and both markers in tumor cells $(\mathrm{P}<0.001))$

Conclusion: PD-L1 and FOXP3 are considered poor prognostic markers in EOC patients with bad impact on progression free survival.

Copy Right, IJAR, 2016,. All rights reserved.

\section{Introduction:-}

Epithelial ovarian cancer (EOC) is the $4^{\text {th }}$ most common cancer in women. The serous and mucinous carcinoma are the commonest EOCsubtypes (1). It was found that EOC microenvironment has an important role in its initiation, progression ad prognosis (2). So it continued to be an important point of research to discover new therapeutic targets for such malignancy. The cells that were in the microenvironment of the EOC may be associated with a good or poor prognosis like tumor-infiltrating lymphocytes (TILs) andT-regulatory cells (Tregs) $(\mathbf{3}, \mathbf{4})$

The PD-1/PD-L1 pathway was a T-cell checkpoint pathway that sent inhibitory signals to $\mathrm{T}$ cells that can inhibit immunity (5). PD-L1, a PD-1 ligand named also B7 homolog 1 (B7-H1) or CD274, is detected in T lymphocytes, B Lmphocytes, dendritic cells, macrophages and various tumor cells (6). PD-L1expression and relation to both pathological, clinical parameters and prognosis were studied in many cancers, but the exact mechanism of how PDL1 and its effect on tumor microenvironments can have a role in cancer immunity is not adequately understood(7). PD-L1 expression in EOC was not done in details and has many conflicting results (8).

Tregs are mature $\mathrm{T}$ lymphocytes that start in the thymus after stimulation of naïve $\mathrm{T}$ cells and responsible for the reduction of autoimmune diseases but their over production will inhibit endogenous protection against infection and tumors (9).Forkhead/winged-helix transcription factor box P3 (Foxp3) is an intracellular molecule specified for Tregs growth and maturation and was found to be the most specific Tregs marker (10).It was found that Foxp3 is not only found in Treg cells of thymus origin but also in cancer cells with different expression pattern which can affect the outcome of cancer patients (11).However, the role of Foxp3 in the prognosis of cancers is still a point of research, so FoxP3+ Tregs are investigated as a prognostic factor and they can be used as a novel therapeutic target.

Aim of our study: was to assess immunohistochemical expression of PD-L1 and FOXP3 in both tumor cells and stroma of epithelial ovarian carcinoma in a trial to detect their prognostic value and relation to survival of patients with such type of cancer.

\section{Patients and Methods}

In our retrospective study fifty archived formalin fixed paraffin embedded blocks of EOC collected from Pathology Department, Faculty of Medicine, Zagazig University in the period from August 2011 to July 2015. We used the tumor-node-metastasis (TNM) and International Federation of Gynecology and Obstetrics (FIGO) classifications for staging of EOC and the WHO grading system for their pathologic grading (12,13). We identified age, grade, stage, lymph node, distant metastasis of the cases, type of surgery which was done for those patients, response to chemotherapy according to RECIST criteria of the patients and the patients outcome from the patients' $\mathrm{s}$ records at Clinical Oncology and Nuclear Medicine and Medical Oncology Departments, Faculty of Medicine, Zagazig University by retrospective examination of the patient's files at the involved departments and the slide files of the pathology department. Our patients had follow-up records for 4 years. Progression was defined by radiological diagnosis according to the RECIST criteria or as doubling of the nadir serum CA-125 (14). The chemotherapy regimen was 6 cycles of paclitaxel $(175 \mathrm{mg} / \mathrm{m} 2)$ with carboplatin (AUC 6), administered every 3 weeks. Histopathological examination and evaluation of PD-L1 and FOXP3 expression in both tumor cells and stroma by using immunohistochemistry were done in the pathology department, Faculty of Medicine, Zagazig University. We 
assessed the relation between their expressions, clinicopathological parameters, response to chemotherapy, survival and prognosis of those patients. Patients with nonepithelial ovarian cancer, patients treated before operation, and patients who were not treated surgically were excluded from this study .Local Research Ethics Committee approval of the study was obtained.

\section{Immunohistochemical staining:}

Immunohistochemical staining was carried out using streptavidin-biotin immunoperoxidase technique (15). The slides were incubated with rabbit monoclonal anti- PD-L1 antibody [28-8] ab205921was used at a dilution of 1:200 and Mouse monoclonal anti-FOXP3 antibody (ab22510) diluted $1 / 50$ at $4^{\circ} \mathrm{C}$ overnight (Abcam, Cambridge, MA, USA). Normal human tonsil is used as a positive control for both PD-L 1and FOXP3 but the negative controls by replacing the primary antibodies by the non-immune serum.

\section{Evaluation of immunohistochemical expressions of PD-L 1: 1. PD-L1 expression in tumor cells;}

The expression of PD-L1 was evaluated according to the intensity of the staining and scored as follows: 0, negative; 1, weak expression; 2, moderate expression and 3, strong expression. Cases with scores 0 and 1 were defined as the low-expression group, and cases with scores 2 and 3 were the high-expression group (16).

\section{PD-L 1expression in tumor infiltrating lymphocytes (TILs)}

Five tumor areas in a 400x magnification (high power fields (HPF) were assessed in areas with higher intratumoral TILs density. The non-tumor areas (e.g. stroma, necrosis) will be separated from areas of pure tumor. PD-L1 positive TILs that were in direct contact with tumor cells were called intratumoral TILs) or PD-L1 positive TILs within the stroma were called stromal TILs. The total number of TILs was added to obtain TILs/5 HPF(17). The cut off (no vs any expression) was used for statistical analysis; no expression in TILs was considered low expression and any expression in TILs considered high expression.

\section{Evaluation of immunohistochemical expressions of FOXP3: \\ 1. FOXP3 expression in tumor cells;}

The expression intensity was classified into four grades as follows: no staining was scored as zero; weak staining was scored as one; moderate staining was scored as two; strong staining was scored as three. Scores for the posi $\neg$ tive cells were as follows: (score 0) means less than or equal 5\% positive cells; (score one) means 6-24\% positive cells; (score two) means $25-49 \%$ positive cells; and (score three) means 50-74\% pos 7 itive cells; and (score four) means more than or equal $75 \%$ positive cells. The scores of percent $\neg$ age and intensity reflect the sums of scores, with total scores of 0 indicated as (-); 1-2 as (+); 3-5 as (++); and 6-7 as (+++) (18). We use total score 5 as a cut off value above which is considered high expression and below which is low expression.

\section{FOXP3 expression in tumor infiltrating lymphocytes (TILs).}

TILs in tumor stroma were counted in ten high-power field (HPF, at _400 magnification). TILs count of more than five per HPF was defined as high TILs, and TILs counts of less than 5 per HPF was defined as low TILs (19).

\section{Statistical analysis:-}

The statistics were done by usage of SPSS 22.0 for windows (SPSS Inc., Chicago, IL, USA) and MedCalc (MedCalc Software bvba 13, Belgium Ostend,). All the Continuous variables were made as the mean (95\%CI). Percent of categorical variables were compared using Chi-square test or by Fisher's exact test. Trends of changes in distribution of the relative frequencies between ordinal data were compared by using Chi-square test. Overall Survival rate (OS) was assessed from the time of cancer diagnosis to death or to the most recent follow-up data. Progression Free Survival rate (PFS) was assessed from time of starting cancer treatment to time of progression or till the most recent follow-up data when patients were known to be progression free. Assessments of OS and PFS rates were made according to our markers. These time-to-event rates were assessed using Kaplan-Meier plots and compared by using two-sided log-rank test.We included patients with suboptimal surgery with residual cancer in response evaluation but the others were excluded. All tests were two sided. A p-value less than 0.05 were considered significant. 


\section{Results:-}

\section{Patient Characteristics}

The clinical characteristics of the 50 ovarian carcinoma (OC) patients that were included in our study are summarized in (Table1) with age ranged from (25-75) years (Mean: $55.08 \pm 10.80$ years), 30(60\%) cases were serous carcinoma, 15(30\%) were mucinous carcinoma and $5(10 \%)$ were carcinoma of other types. The most prevalent stage is stage III which is present in 27 patients (54\%) whereas stage II and IV are present in 7(14\%) patients and 14 (28\%) patients respectively. Only two patients had stage Ic. Forty three patients (86\%) had high grade OC. Lymph node and distant metastasis are present in 33(66\%) patients and $14(28 \%)$ patients respectively .The suboptimal surgery with residual disease more than $1 \mathrm{~cm}$, was present in $22(44 \%)$ patients but optimal surgery was done for 28 (56\%) patients . The median of follow up duration was 25.50 . While its range was $10-48$ months .

Table 1:-clinopathological parameters,PDL-1\& FOXP3 immunohistochemical expressions and outcome of our patients

\begin{tabular}{|c|c|c|c|c|c|}
\hline Characteristics & Number & Percent & Characteristics & Number & Percent \\
\hline Age (years) & & & PD-L1 in TILs & & \\
\hline Mean \pm SD & 55.08 & \pm 10.80 & Low & 30 & $60 \%$ \\
\hline Median (Range) & 56.50 & $(25-75)$ & High & 20 & $40 \%$ \\
\hline$\leq 60$ years & 39 & $78 \%$ & FOXP3 in TILs & & \\
\hline \multirow[t]{2}{*}{$>60$ years } & 11 & $22 \%$ & Low & 30 & $60 \%$ \\
\hline & & & High & 20 & $40 \%$ \\
\hline FIGO stage & & & PD-L1 \& FOXP3 in TILs & & \\
\hline Stage IC & 2 & $4 \%$ & Low/Low & 17 & $34 \%$ \\
\hline Stage II & 7 & $14 \%$ & Low/High & 13 & $26 \%$ \\
\hline Stage III & 27 & $54 \%$ & High/Low & 13 & $26 \%$ \\
\hline Grade IV & 14 & $28 \%$ & High/High & 7 & $14 \%$ \\
\hline Histological type & & & Surgery & & \\
\hline Serous & 30 & $60 \%$ & Suboptimal & 22 & $44 \%$ \\
\hline Mucinous & 15 & $30 \%$ & Optimal & 28 & $56 \%$ \\
\hline Other & 5 & $10 \%$ & & & \\
\hline Grade & & & Residual & & \\
\hline Low grade & 7 & $14 \%$ & Absent & 28 & $56 \%$ \\
\hline High grade & 43 & $86 \%$ & Present & 22 & $44 \%$ \\
\hline Lymph node & & & $\begin{array}{l}\text { Response (in patient ur } \\
\text { surgery, } \mathbf{N}=22 \text { ) }\end{array}$ & derwent & suboptimal \\
\hline Negative & 17 & $34 \%$ & $\mathrm{CR}$ & 11 & $50 \%$ \\
\hline Positive & 33 & $66 \%$ & $\overline{\mathrm{PR}}$ & 4 & $18.2 \%$ \\
\hline Distant metastasis & & & SD & 4 & $18.2 \%$ \\
\hline Negative & 36 & $72 \%$ & NR & 3 & $13.6 \%$ \\
\hline \multirow[t]{2}{*}{ Positive } & 14 & $28 \%$ & OAR & 15 & $68.2 \%$ \\
\hline & & & NR & 7 & $31.8 \%$ \\
\hline PD-L1 in tumor cells & & & Follow-up duration (months) & & \\
\hline Low & 19 & $38 \%$ & Mean \pm SD & 24.70 & \pm 10.61 \\
\hline High & 31 & $62 \%$ & Median (Range) & 24 & $(9-48)$ \\
\hline FOXP3 in tumor cells & & & Progression & & \\
\hline Low & 25 & $50 \%$ & Absent & 15 & $30 \%$ \\
\hline High & 25 & $50 \%$ & Present & 35 & $70 \%$ \\
\hline $\begin{array}{l}\text { PD-L1 \& FOXP3 in tumor } \\
\text { cells }\end{array}$ & & & Mortality & & \\
\hline Low/Low & 12 & $24 \%$ & Alive & 27 & $54 \%$ \\
\hline Low/High & 7 & $14 \%$ & Died & 23 & $46 \%$ \\
\hline High/Low & 13 & $26 \%$ & & & \\
\hline High/High & 18 & $36 \%$ & & & \\
\hline
\end{tabular}


PDL-1 immunoexpression and their correlation with clinicopathological features of OC patients: (Fig 5)

1.PDL-1 expression in tumor cells

High cytoplasmic expression of PD-L1 in tumor cells was detected in 31 out of 50(62\%) cases of our patients, and it was significantly positively correlated with; histopathological type $(\mathrm{p}=0.011)$, grade, stage of the tumor and lymph node metastases $(\mathrm{p}=0.001)$, type of surgery and absence of residual disease after surgery $(\mathrm{P}=0.010)$.No significant correlation was found between PD-L1 in tumer cells expression and distant metastases or age of the patients (Tables 2, 4).

\section{PDL-1 expression in tumor infiltrating lymphocytes (TILs)}

High cytoplasmic expression of PDL-1 in TILs was detected in 20 out of 50(40\%) cases of our patients and it was significantly positively correlated with grade $(\mathrm{p}=0.033)$ and stage of the tumor $(\mathrm{p}=0.029)$. No significant correlation was found between PD-L1 expression, histopathological type of the tumor, lymph node metastases, distant metastases or age of the patients, type of surgery and residual disease after surgery (Tables 2,4).

Table 2:- correlations between clinopathological parameters PDL-1\& FOXP3 immunohistochemical expressions in tumor cells and TILs in our patients

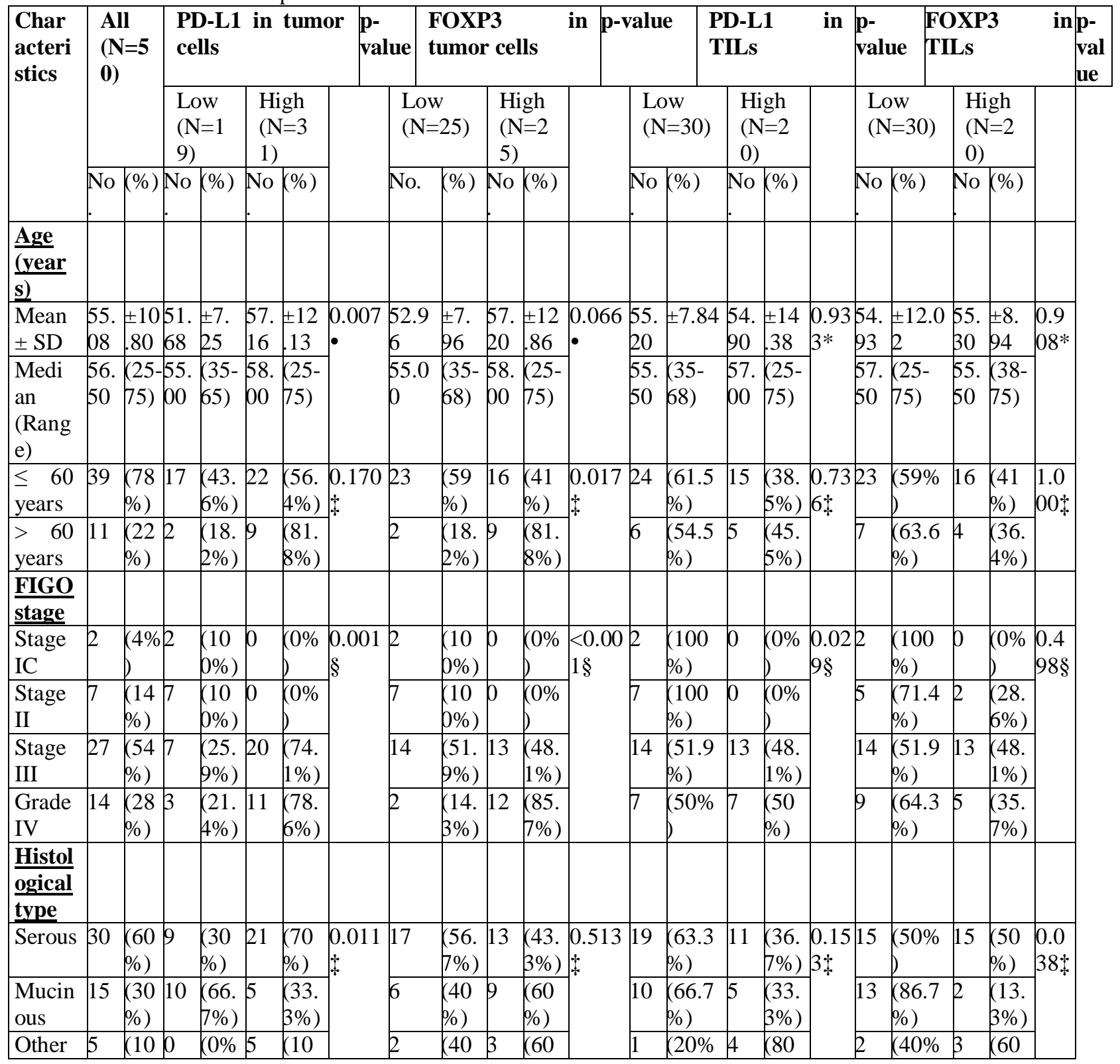




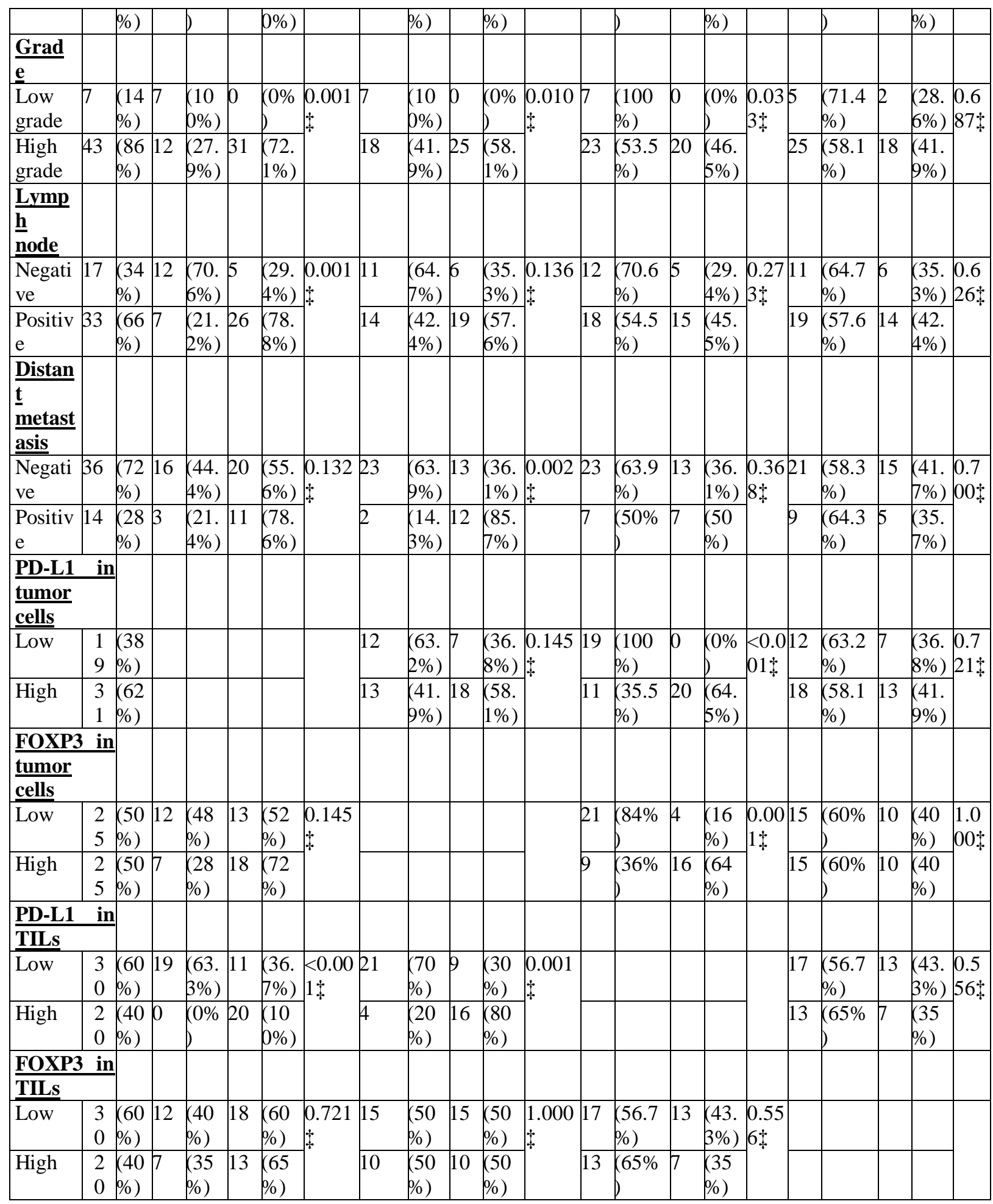

FOXP3 immunoexpression and its correlation with clinicopathological features of EOC patients: (Fig 5) 1.FOXP3 expression in tumor cells

High nuclear expression of FOXP3 in tumor cells was detected in 25out of 50(50\%) cases of our patients, and it was significantly positively correlated with; age of the patients $(\mathrm{p}=0.017)$, grade $(\mathrm{p}=0.010)$, distant metastases $(\mathrm{p}=0.002)$. and stage of the tumor $(\mathrm{p}<0.001)$. No significant correlation was found between FOXP3 expression, histopathological type or lymph node metastases, type of surgery and residual disease after surgery (Tables 2,4 ). 


\section{FOXP3 expression in tumor infiltrating lymphocytes (TILs)}

High nuclear expression of FOXP3 in TILs was detected in 20 out of 50(40\%) cases of our patients and it was significantly positively correlated with histopathological type of the tumor $(\mathrm{p}=0.038)$. No significant correlation was found between FOXP3 expression, grade and stage of the tumor, lymph node metastases, distant metastases or age of the patients, type of surgery and residual disease after surgery . There were highly significant statistical relations were found between PD-L1 expression in both tumor cells and TILs $(\mathrm{p}<0.001)$ There were highly significant statistical relations between expression of PD-L1 expression in TILs and FOXP3 expression in tumor cells $(\mathrm{p}=0.001)$ (Tables 2 ,4).

Table 3:- correlations between clinopathological parameters, PDL-1\& FOXP3 immunohistochemical expressions in tumor cells and TILs in our patients

\begin{tabular}{|c|c|c|c|c|c|c|c|c|c|c|c|c|c|c|c|c|c|c|c|c|c|c|}
\hline \multirow{3}{*}{\begin{tabular}{|l|}
$\begin{array}{l}\text { Charact } \\
\text { eristics }\end{array}$ \\
\end{tabular}} & \multirow{2}{*}{\multicolumn{2}{|c|}{$\begin{array}{l}\text { All } \\
(\mathbf{N}=\mathbf{5 0} \\
)\end{array}$}} & \multicolumn{10}{|c|}{ PD-L1\& FOXP3 in tumor cells } & \multicolumn{2}{|c|}{$\begin{array}{l}\mathrm{p} \text { - } \\
\text { value }\end{array}$} & \multicolumn{7}{|c|}{ PD-L1\& FOXP3 in TILs } & \multirow{2}{*}{$\begin{array}{l}\text { p- } \\
\text { va } \\
\text { ue } \\
\end{array}$} \\
\hline & & & \multicolumn{2}{|c|}{$\begin{array}{l}\text { Low/L } \\
\text { ow } \\
(\mathrm{N}=12) \\
\end{array}$} & \multicolumn{2}{|c|}{\begin{tabular}{|l|} 
Low/H \\
igh \\
$(\mathrm{N}=7)$ \\
\end{tabular}} & \multicolumn{2}{|c|}{\begin{tabular}{|l|} 
High/L \\
ow \\
$(\mathrm{N}=13)$ \\
\end{tabular}} & \multicolumn{2}{|c|}{$\begin{array}{l}\mathrm{High} / \mathrm{H} \\
\text { igh } \\
(\mathrm{N}=18)\end{array}$} & & \multicolumn{3}{|c|}{$\begin{array}{l}\text { Low/Low } \\
(\mathrm{N}=17)\end{array}$} & \multicolumn{2}{|c|}{$\begin{array}{l}\text { Low/H } \\
\text { igh } \\
(\mathrm{N}=13)\end{array}$} & \multicolumn{2}{|c|}{\begin{tabular}{|l|} 
High/L \\
ow \\
$(\mathrm{N}=13)$
\end{tabular}} & \multicolumn{2}{|c|}{\begin{tabular}{|l}
$\mathrm{High} / \mathrm{H}$ \\
igh \\
$(\mathrm{N}=7)$ \\
\end{tabular}} & & \\
\hline & No & $(\%)$ & No. & $(\%)$ & No. & $(\%)$ & & $(\%)$ & No. & $(\%)$ & & $\mathrm{No}$ & Jo. & $(\%)$ & No. & $(\%)$ & & $(\%)$ & No. & $(\%)$ & & \\
\hline $\begin{array}{l}\text { Age } \\
\text { (years) }\end{array}$ & & & & & & & & & & & & & & & & & & & & & & \\
\hline $\begin{array}{l}\text { Mean } \pm \\
\text { SD }\end{array}$ & 55. & $\begin{array}{l} \pm 10 . \\
80\end{array}$ & $\begin{array}{l}48 . \\
08\end{array}$ & \pm 6.2 & $\begin{array}{l}57 . \\
85\end{array}$ & \pm 3.9 & 57. & $\begin{array}{l} \pm 6.7 \\
0\end{array}$ & $\begin{array}{l}56 . \\
94\end{array}$ & $\begin{array}{l}+15 . \\
09\end{array}$ & & $\begin{array}{c}0654 \\
2\end{array}$ & 4.8 & \pm 9.24 & $\begin{array}{l}55 . \\
69\end{array}$ & $\begin{array}{l} \pm 5.8 \\
6\end{array}$ & $\begin{array}{l}55 . \\
07\end{array}$ & $\begin{array}{l} \pm 15 \\
34\end{array}$ & $\begin{array}{l}54 . \\
57\end{array}$ & $\begin{array}{l} \pm 13 . \\
55\end{array}$ & 0.891 & \\
\hline $\begin{array}{l}\text { Median } \\
\text { (Range) }\end{array}$ & $\begin{array}{l}56 . \\
50\end{array}$ & $\begin{array}{l}(25- \\
75)\end{array}$ & $\begin{array}{l}45 . \\
50\end{array}$ & $\begin{array}{l}35- \\
56)\end{array}$ & $\begin{array}{l}55 . \\
00\end{array}$ & $\begin{array}{l}(55- \\
65)\end{array}$ & $\begin{array}{l}58 . \\
00\end{array}$ & $\begin{array}{l}(47- \\
68)\end{array}$ & 58 & $\begin{array}{l}(25- \\
75)\end{array}$ & & & 5.0 & $\begin{array}{l}(35- \\
68)\end{array}$ & $\begin{array}{l}56 . \\
00\end{array}$ & $\begin{array}{l}(45- \\
65)\end{array}$ & $\begin{array}{l}58 . \\
00\end{array}$ & $\begin{array}{l}(25- \\
75)\end{array}$ & $\begin{array}{l}49 . \\
\text { bo }\end{array}$ & $\begin{array}{l}(38- \\
75)\end{array}$ & & \\
\hline $\begin{array}{l}\leq \quad 60 \\
\text { years }\end{array}$ & 39 & $\begin{array}{l}(78 \\
\%)\end{array}$ & 12 & $\begin{array}{l}(30.8 \\
\%)\end{array}$ & 5 & $\begin{array}{l}(12.8 \\
\%)\end{array}$ & 11 & $\begin{array}{l}(28.2 \\
\%)\end{array}$ & 11 & $\begin{array}{l}(28.2 \\
\%)\end{array}$ & & 7613 & & $\begin{array}{l}(33.3 \\
\%)\end{array}$ & 11 & $\begin{array}{l}(28.2 \\
\%)\end{array}$ & 210 & $\begin{array}{l}(25.6 \\
\%)\end{array}$ & 55 & $\begin{array}{l}(12.8 \\
\%)\end{array}$ & 0.910 & \\
\hline $\begin{array}{ll} & 60 \\
\text { years }\end{array}$ & 11 & $\begin{array}{l}(22 \\
\%)\end{array}$ & 0 & $(0 \%)$ & 2 & $\begin{array}{l}(18.2 \\
\%)\end{array}$ & 2 & $\begin{array}{l}(18.2 \\
\%)\end{array}$ & & $\begin{array}{l}63.6 \\
\%)\end{array}$ & & 4 & & $\begin{array}{l}(36.4 \\
\%)\end{array}$ & 2 & $\begin{array}{l}(18.2 \\
\%)\end{array}$ & 3 & $\begin{array}{l}(27.3 \\
\%)\end{array}$ & 32 & $\begin{array}{l}(18.2 \\
\%)\end{array}$ & & \\
\hline FIGO & & & & & & & & & & & & & & & & & & & & & & \\
\hline$\overline{\text { Stage IC }}$ & 2 & (4\%) & 2 & $\begin{array}{l}(100 \\
\% \%)\end{array}$ & 0 & $(0 \%)$ & 0 & $(0 \%)$ & 0 & $(0 \%)$ & $\begin{array}{l}<0 \\
01\end{array}$ & $\S{ }^{0}$ & & (100\% & 60 & $(0 \%)$ & 0 & $(0 \%)$ & 0 & $(0 \%)$ & $\begin{array}{l}0.020 \\
\S\end{array}$ & \\
\hline Stage II & 7 & $\begin{array}{l}(14 \\
\%)\end{array}$ & 7 & $\begin{array}{l}(100 \\
\%)\end{array}$ & 0 & $(0 \%)$ & 0 & $(0 \%)$ & 0 & $(0 \%)$ & & 5 & & $\begin{array}{l}(71.4 \\
\%)\end{array}$ & 2 & $\begin{array}{l}(28.6 \\
\%)\end{array}$ & 50 & $(0 \%)$ & 0 & $(0 \%)$ & & \\
\hline Stage III & 27 & $\begin{array}{l}(54 \\
\%)\end{array}$ & 3 & $\begin{array}{l}(11.1 \\
\%)\end{array}$ & 4 & $\begin{array}{l}(14.8 \\
\%)\end{array}$ & 11 & $\begin{array}{l}(40.7 \\
\%)\end{array}$ & 9 & $\begin{array}{l}(33.3 \\
\%)\end{array}$ & & 5 & & $\begin{array}{l}(18.5 \\
\%)\end{array}$ & 9 & $\begin{array}{l}(33.3 \\
\%)\end{array}$ & 39 & $\begin{array}{l}(33.3 \\
\%)\end{array}$ & 34 & $\begin{array}{l}(14.8 \\
\%)\end{array}$ & & \\
\hline Grade IV & 14 & $\begin{array}{l}(28 \\
\%)\end{array}$ & 0 & $(0 \%)$ & $\beta$ & $\begin{array}{l}(21.4 \\
\%)\end{array}$ & 2 & $\begin{array}{l}(14.3 \\
\%)\end{array}$ & & $\begin{array}{l}(64.3 \\
\%)\end{array}$ & & 5 & & $\begin{array}{l}35.7 \\
\%)\end{array}$ & 2 & $\begin{array}{l}(14.3 \\
\%)\end{array}$ & 3 & $\begin{array}{l}(28.6 \\
\%)\end{array}$ & 63 & $\begin{array}{l}(21.4 \\
\%)\end{array}$ & & \\
\hline $\begin{array}{l}\text { Histolog } \\
\text { ical type } \\
\text { ingl }\end{array}$ & & & & & & & & & & & & & & & & & & & & & & \\
\hline Serous & 30 & $\begin{array}{l}(60 \\
\%)\end{array}$ & 8 & $\begin{array}{l}26.7 \\
\%)\end{array}$ & 1 & $(3.3$ & 9 & $30 \%$ & 612 & (40\% & & 0198 & & $\begin{array}{l}(26.7 \\
\%)\end{array}$ & 11 & $\begin{array}{l}(36.7 \\
\%)\end{array}$ & 77 & $\begin{array}{l}(23.3 \\
\%)\end{array}$ & 34 & $\begin{array}{l}(13.3 \\
\%)\end{array}$ & 0.059 & \\
\hline Mucinous & 15 & $\begin{array}{l}(30 \\
\%)\end{array}$ & 4 & $\begin{array}{l}(26.7 \\
\%)\end{array}$ & 6 & $(40 \%$ & 2 & $\begin{array}{l}(13.3 \\
\%)\end{array}$ & & $20 \%$ & & 9 & & $(60 \%)$ & 1 & $\begin{array}{l}(6.7 \\
\%)\end{array}$ & 4 & $\begin{array}{l}(26.7 \\
\%)\end{array}$ & & $\begin{array}{l}(6.7 \\
\%)\end{array}$ & & \\
\hline Other & 5 & $\begin{array}{l}(10 \\
\%)\end{array}$ & 0 & $(0 \%)$ & 0 & $(0 \%)$ & 2 & $\int^{(40 \%}$ & 63 & $60 \%$ & & 0 & & $(0 \%)$ & 1 & $20 \%$ & 62 & $40 \%$ & 62 & (40\% & & \\
\hline Grade & & & & & & & & & & & & & & & & & & & & & & \\
\hline $\begin{array}{l}\text { Low } \\
\text { grade }\end{array}$ & 7 & $\begin{array}{l}(14 \\
\%)\end{array}$ & 7 & $\begin{array}{l}(100 \\
\%)\end{array}$ & 0 & $(0 \%)$ & 0 & $(0 \%)$ & 0 & $(0 \%)$ & $\begin{array}{l}<0 \\
01\end{array}$ & $\begin{array}{ll}05 \\
+\end{array}$ & & $\begin{array}{l}(71.4 \\
\%)\end{array}$ & 2 & $\begin{array}{l}(28.6 \\
\%)\end{array}$ & 0 & $(0 \%)$ & 0 & $(0 \%)$ & $\begin{array}{l}0.085 \\
\vdots \\
+\end{array}$ & \\
\hline $\begin{array}{l}\text { High } \\
\text { grade }\end{array}$ & 43 & $\begin{array}{l}86 \\
\%)\end{array}$ & 5 & $\begin{array}{l}(11.6 \\
\%)\end{array}$ & 7 & $\begin{array}{l}(16.3 \\
\%)\end{array}$ & 13 & $\begin{array}{l}(30.2 \\
\%)\end{array}$ & 18 & $\begin{array}{l}(41.9 \\
\%)\end{array}$ & & 12 & & $\begin{array}{l}27.9 \\
\%)\end{array}$ & 11 & $\begin{array}{l}(25.6 \\
\%)\end{array}$ & 13 & $\begin{array}{l}(30.2 \\
\%)\end{array}$ & 27 & $\begin{array}{l}(16.3 \\
\%)\end{array}$ & & \\
\hline $\begin{array}{l}\text { Lymph } \\
\text { node }\end{array}$ & & & & & & & & & & & & & & & & & & & & & & \\
\hline Negative & 17 & $\begin{array}{l}(34 \\
\%)\end{array}$ & 8 & $\begin{array}{l}(47.1 \\
6 \%)\end{array}$ & 4 & $\begin{array}{l}23.5 \\
\%)\end{array}$ & 3 & $\begin{array}{l}(17.6 \\
\%)\end{array}$ & & $\begin{array}{l}(11.8 \\
\%)\end{array}$ & & 078 & & $\begin{array}{l}(47.1 \\
\%)\end{array}$ & 4 & $\begin{array}{l}(23.5 \\
\%)\end{array}$ & 3 & $\begin{array}{l}(17.6 \\
\%)\end{array}$ & & $\begin{array}{l}(11.8 \\
\%)\end{array}$ & 0.545 & \\
\hline Positive & 33 & (66 & 4 & (12.1 & 3 & $(9.1$ & 10 & $(30.3$ & 16 & $(48.5$ & & 9 & & $(27.3$ & 9 & \begin{tabular}{|l|}
$(27.3$ \\
\end{tabular} & 10 & (30.3 & 35 & $(15.2$ & & \\
\hline
\end{tabular}




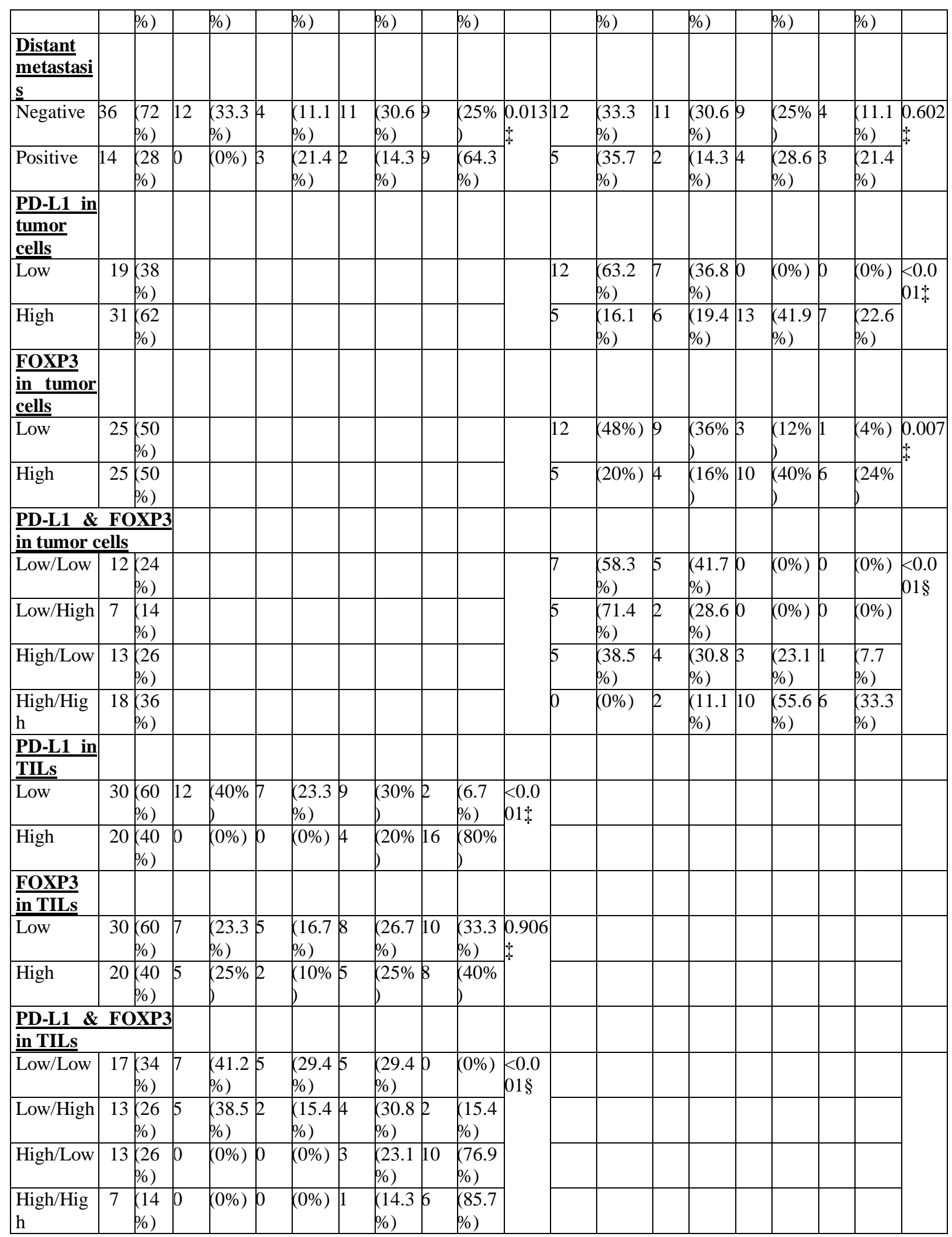


Correlation between the clinopathological parameters on immunohistochemical staining for PD-L1 and FOXP3 in tumor cells and TILs in epithelial ovarian carcinoma women

The combination between the two markers in tumor cells were significant with age (P0.006), grade and stage $(\mathrm{P}<0.001)$, histological type $(\mathrm{P}=0.019)$, LN metastasis $(\mathrm{P}=0.007)$, distant metastasis $(\mathrm{P}=0.013)$, type of surgery and residual disease after operation $(\mathrm{P}=0.020)$.

The combination between the markers in TILs were significant with stage $(\mathrm{P}=0.020)$ only.

No significant correlation was found between combinations of the markers in TILs with the age, grade and stage, histological type, LN metastasis, distant metastasis, type of surgery or residual disease after operation .

There were highly significant statistical relations were found between expression of both markers in tumor cells and PD-L1 in TILs and both PD-L1 \&FOXP3 in TILs ( $<<0.001)$.

There were highly significant statistical relations between expression of both markers in TILs and PD-L1 in tumor cells $(\mathrm{P}<0.001)$, FOXP3 expression in tumor cells $(\mathrm{p}=0.007)$ and both markers in tumor cells $(\mathrm{P}<0.001)$ (Tables 3, 5).

The response and the outcome and their correlation with the markers (Tables $1,4 \& 5$, Figs 1, 2, 3\& 4)

Patients with residual disease (22patients) were included in evaluation of response otherwise other patients were excluded. Fifteen (68.2\%) patients had response to treatment; $11(50 \%)$ patients had CR whereas $4(18.2 \%)$ patients had PR .Only 7 (31.8\%) patients had no response (SD\&NR) .Overall 35 patients (70\%) had progression and 23 (46\%) patients died. Table 1There were high response rate and less progression and less mortality in patients with low PD-L1 expression in tumor cells or TILs but with no significant correlation between them with each marker or their combination with FOXP3. There were high $4 \mathrm{y}$ - DFS and 4y-OS in patients with low PD-L1 expression in tumor cells or TILs but with no significant correlation with each marker . Combined low PDL1\& FOXP3 expressions in tumor cells were significantly associated with higher progression free survival (PFS) $(\mathrm{p}<0.045)$. There were high response rate and less progression in patients with low FOXP3 expression in tumor cells or TILs but the mortality was less in patients with low FOXP3 in tumor cells only, with no significant correlation between them with each marker or their combination with PD-L1. The mortality was higher in patients with low FOXP3 in TILs only but without any significance. There were high $4 \mathrm{y}$ - DFS in patients with low FOXP3 expression in tumor cells or TILs but with no significant correlation with each marker. However there were low $4 \mathrm{y}-\mathrm{OS}$ in patients with low FOXP3 expression in tumor cells or TILs but with no significant correlation with each marker . Combined low PD-L1\& FOXP3 expressions in tumor cells were significantly associated with higher progression free survival (PFS) ( $\mathrm{p}<0.045)$. so:-

- There are no significant correlations between PD-L1 or FOXP3 expression or their combination in tumor cells or in TILs with response to treatment, progression, or mortality $(\mathrm{P}>0.05)$

- There are no significant correlations between PD-L1 expression in tumor cells or TILs with progression free survival (PFS)\& overall survival $(\mathrm{OS})$ rates $(\mathrm{p}>0.05)$.

- There are no significant correlations between FOXP3 expression in tumor cells or in TILs with overall survival (OS) or progression free survival (PFS) $(\mathrm{P}>0.05)$

- $\quad$ Combined low PD-L1\& FOXP3 expressions in tumor cells were significantly associated with higher progression free survival (PFS) $(\mathrm{p}<0.045)$.

Table 4:- correlations between PDL-1\& FOXP3 immunohistochemical expressions in tumor cells and TILs and outcome of our patients

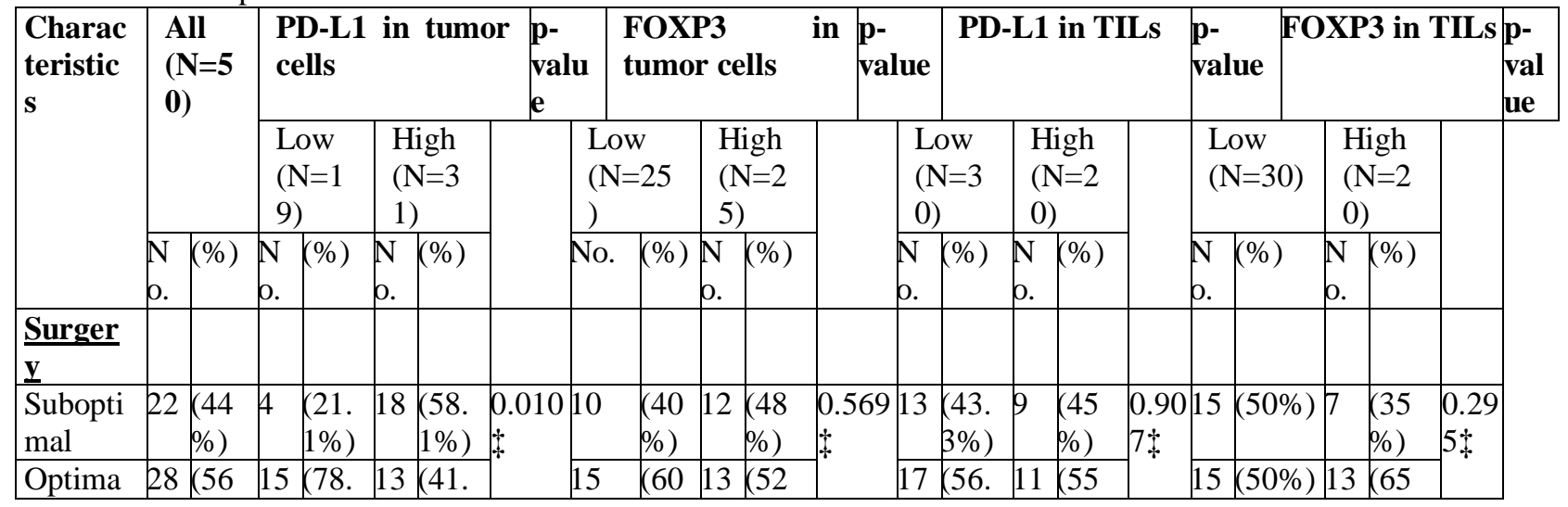




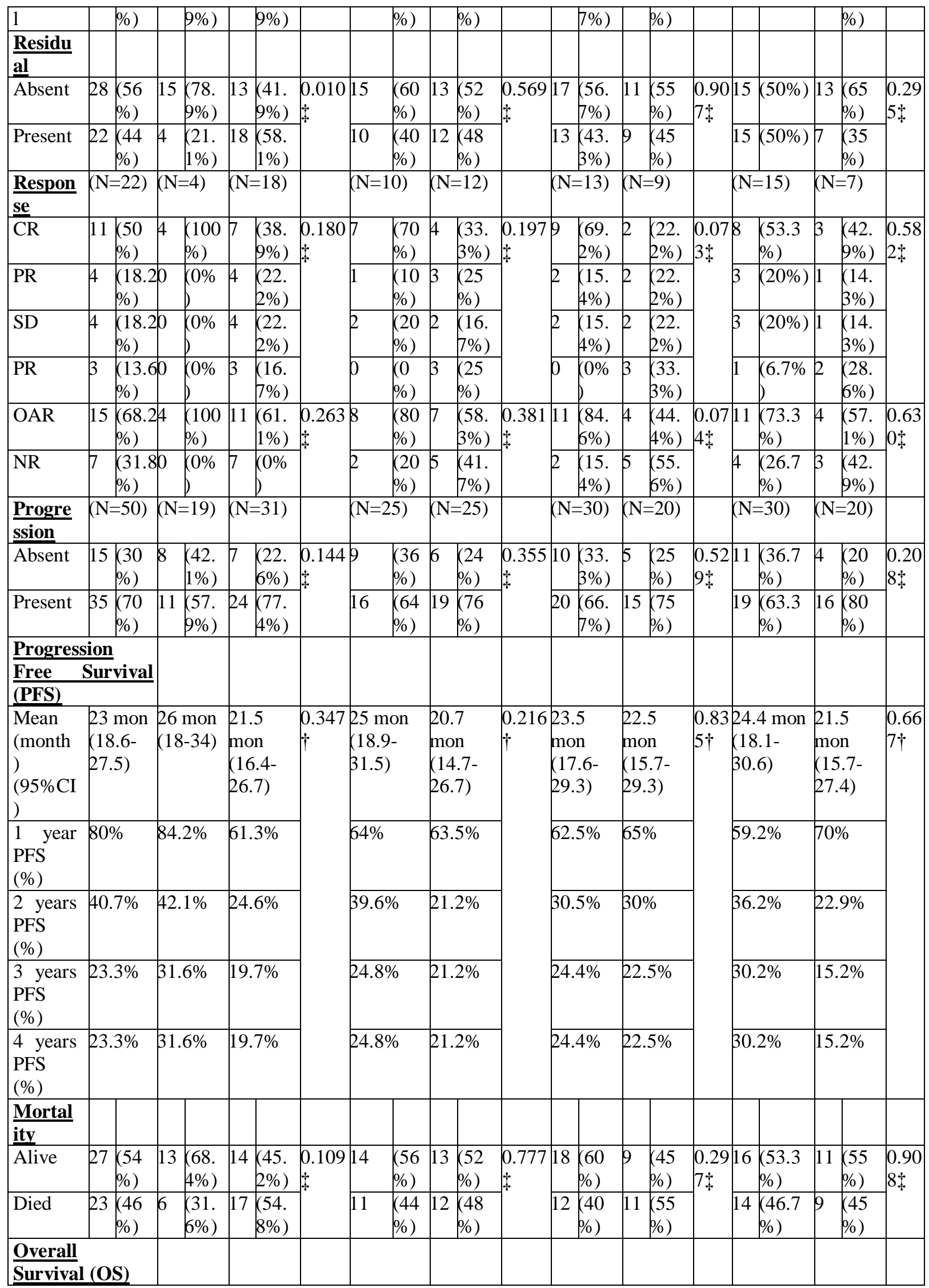




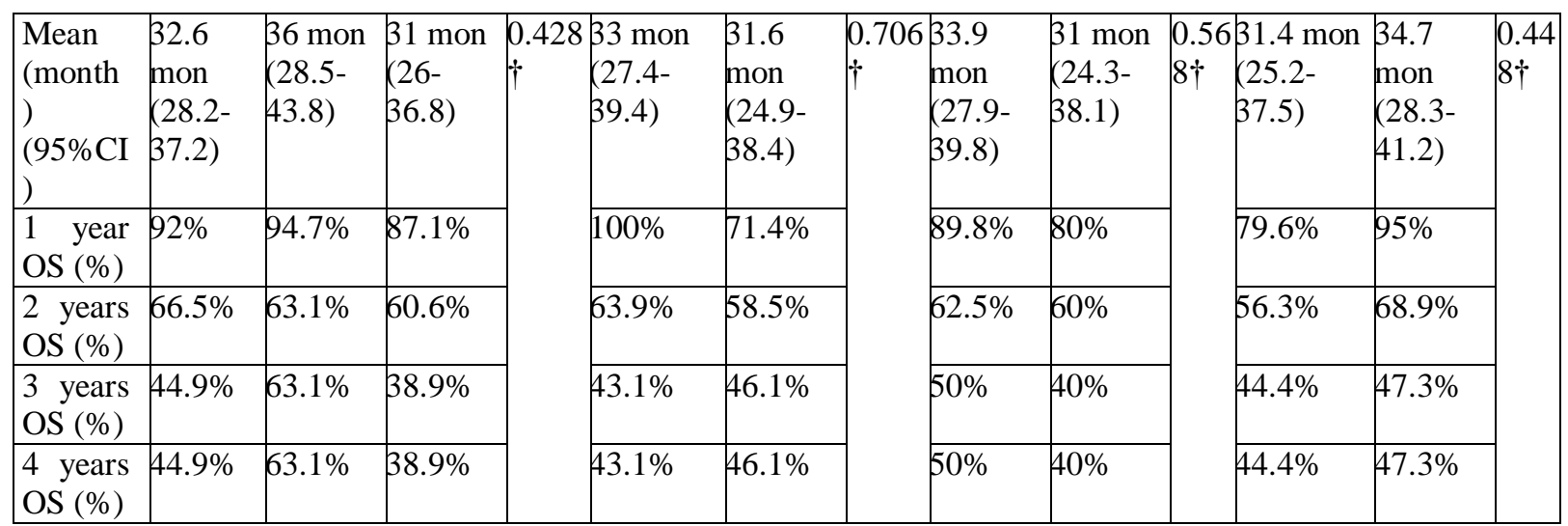

Table (5): correlations between PDL-1\& FOXP3 immunohistochemical expressions in tumor cells and TILs and outcome of our patients

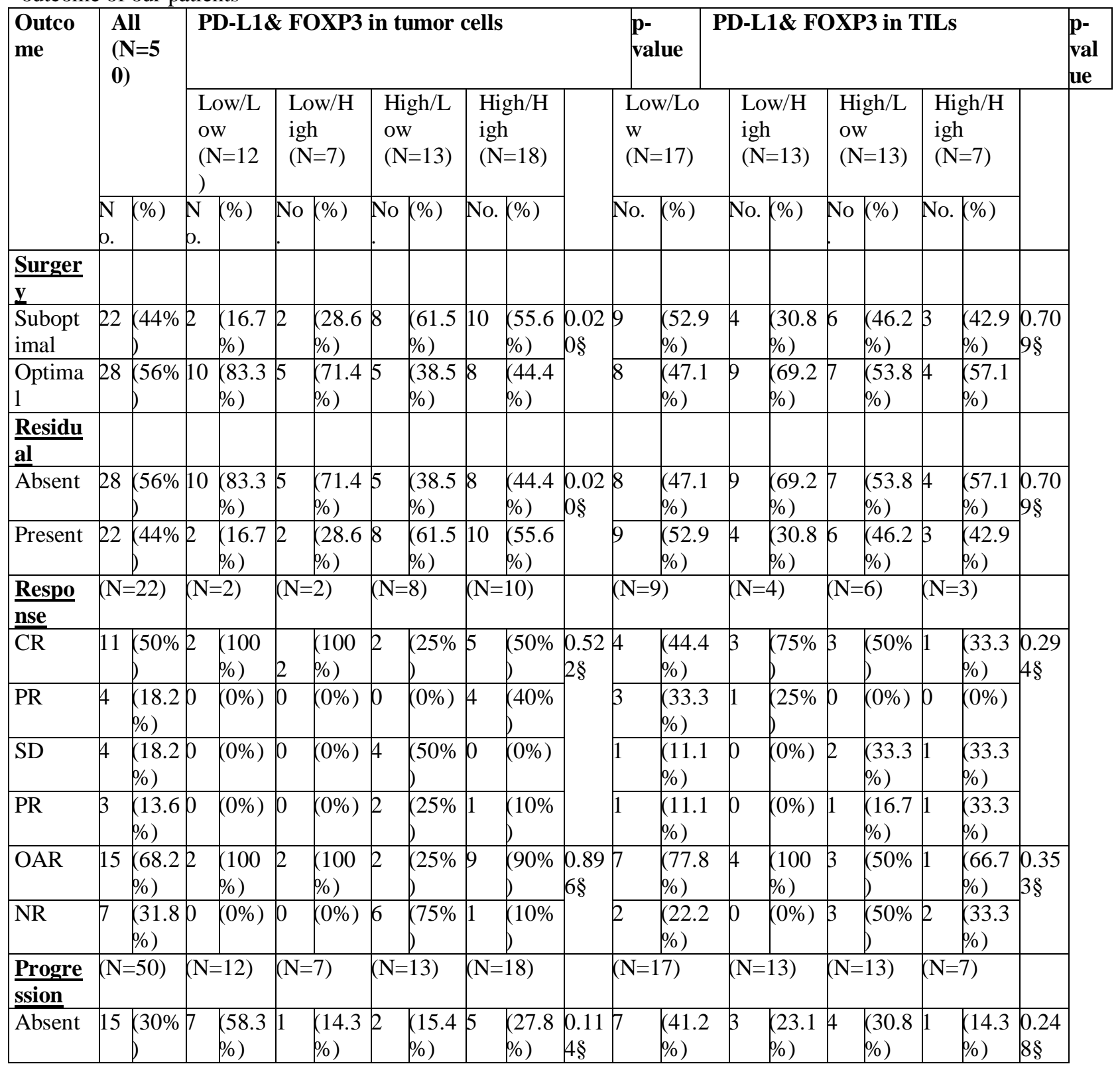




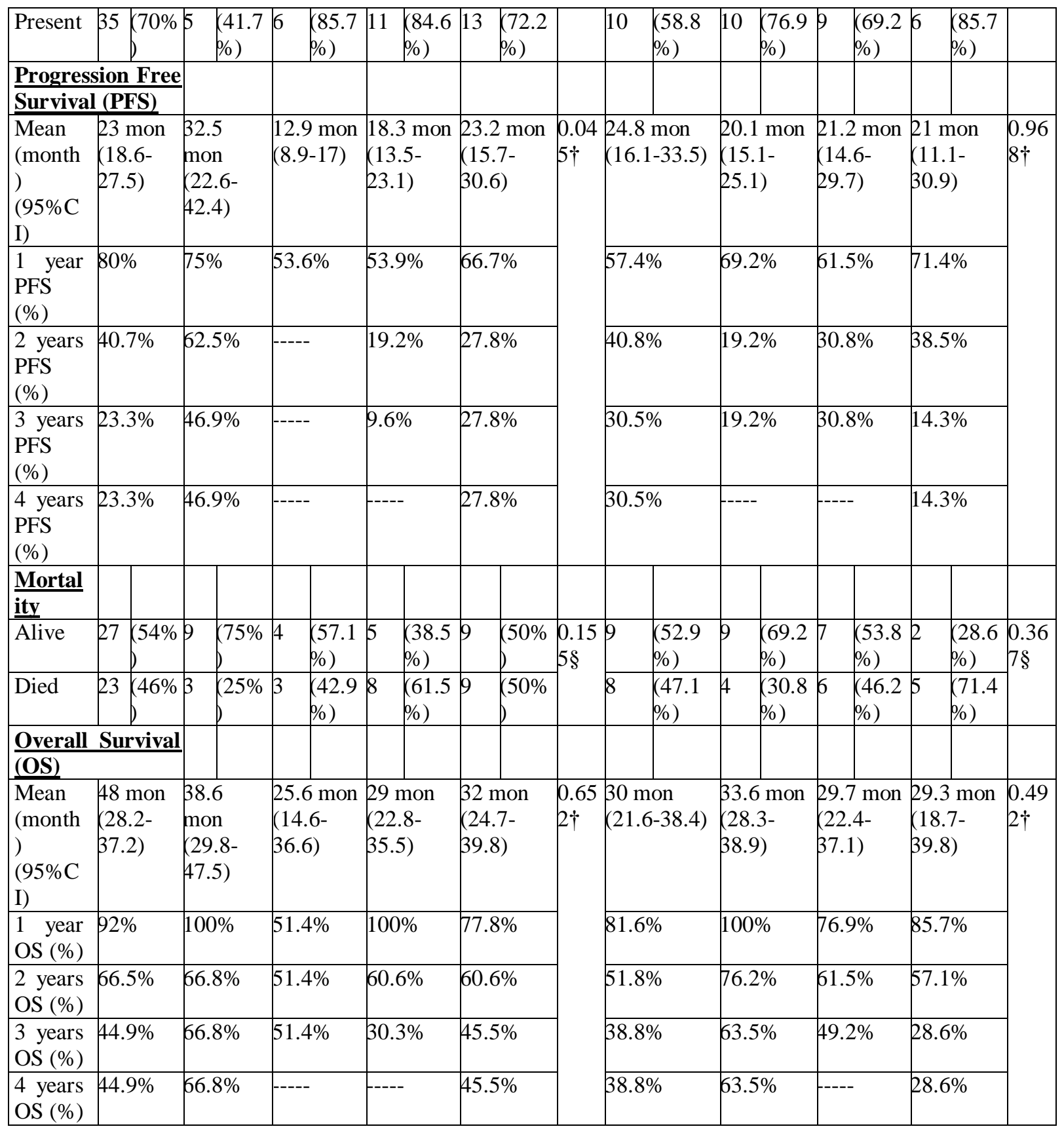




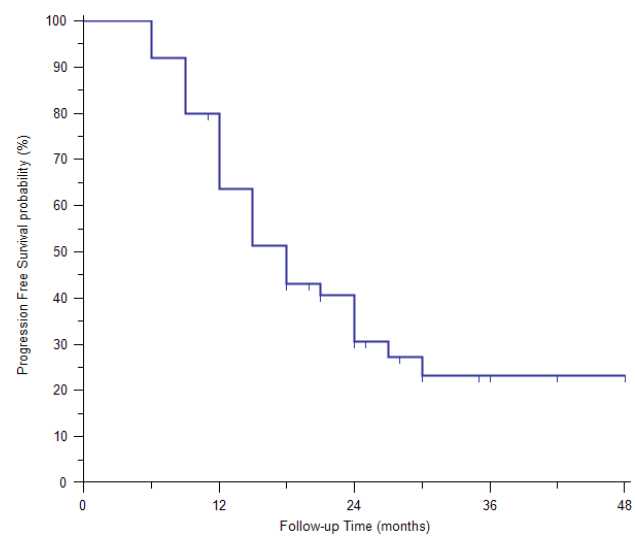

(A)
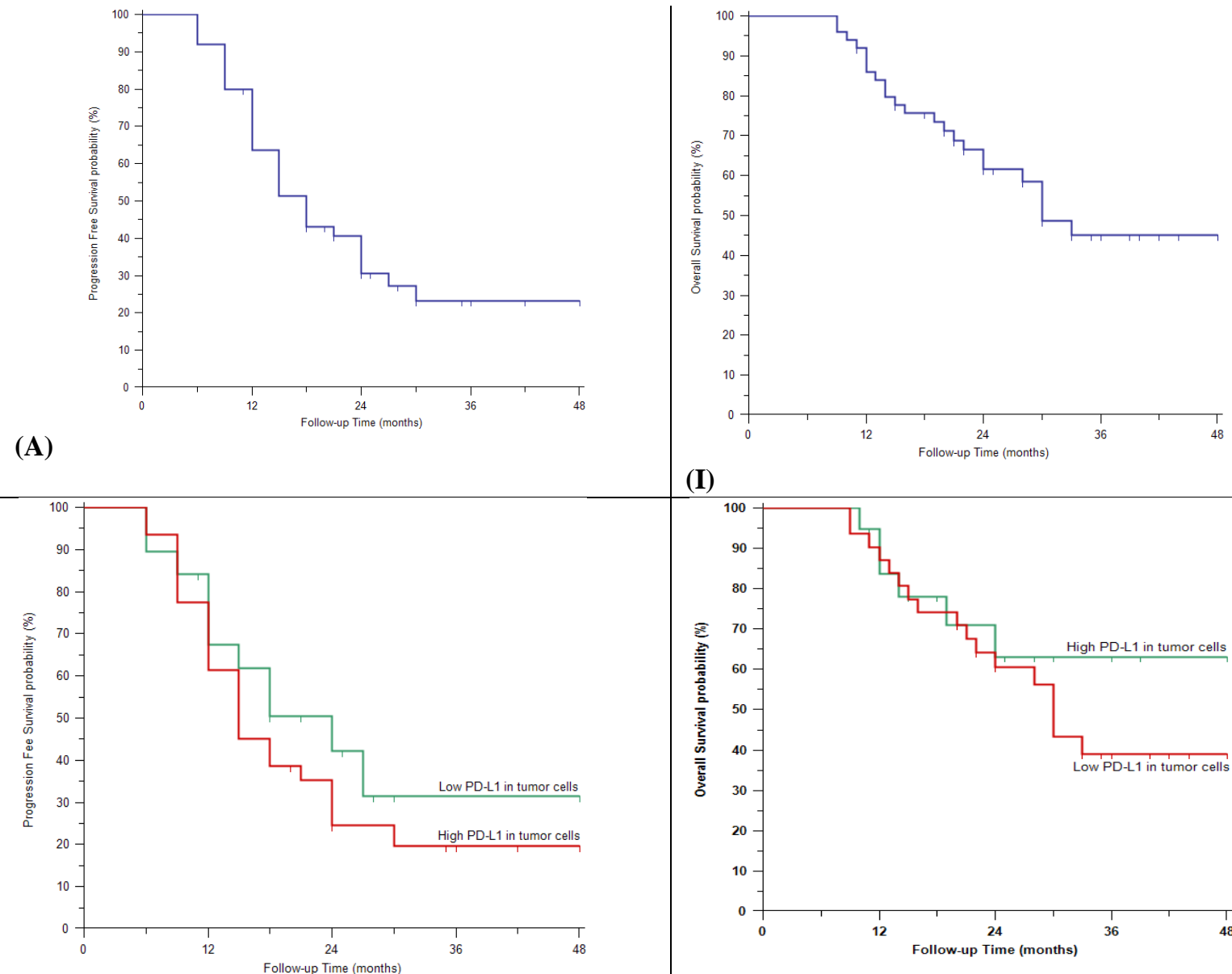

(I)

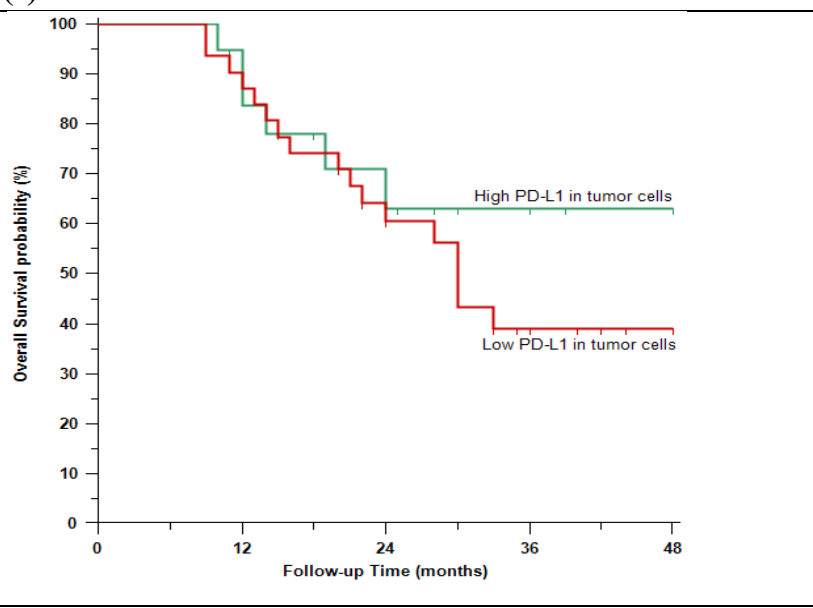

(B)

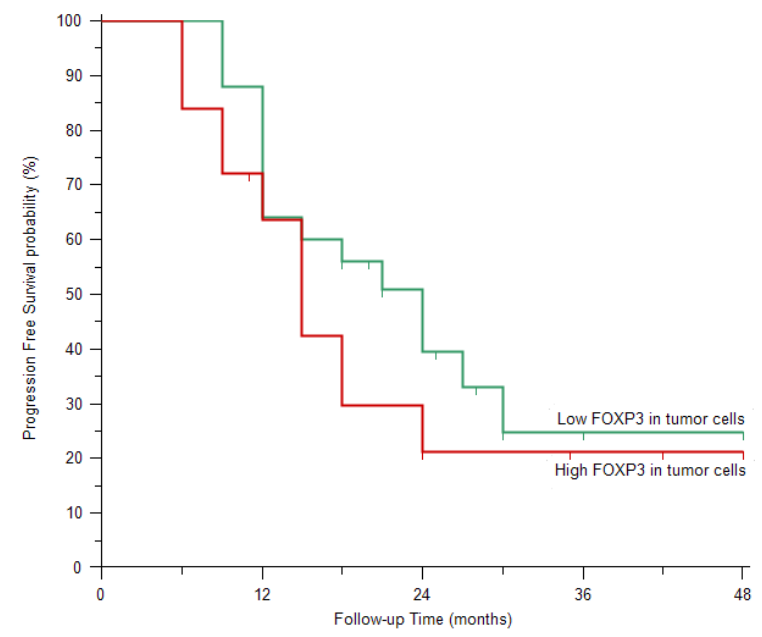

(C)
(J)

Figure 1:- Kaplan Meier plot, Left panel: Progression Free Survival, Right panel: Overall Survival; (A \& I) All studied patients, (B \& J) Stratified by PD-L1 in tumor cells.

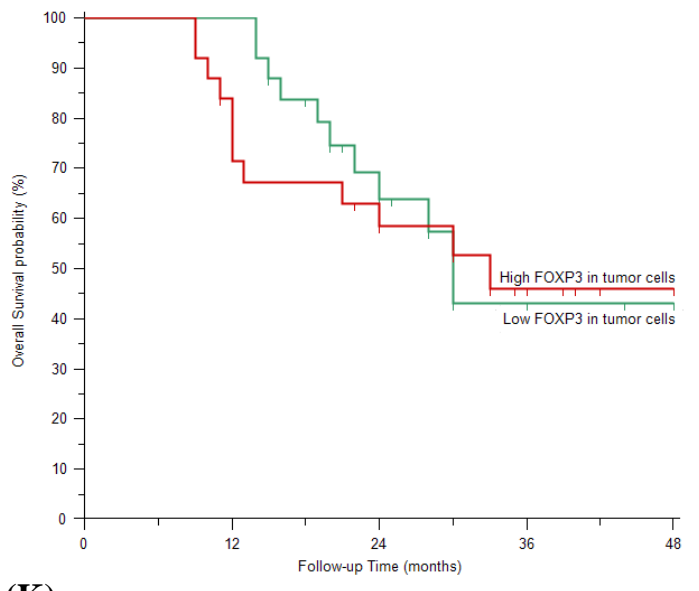

(K) 


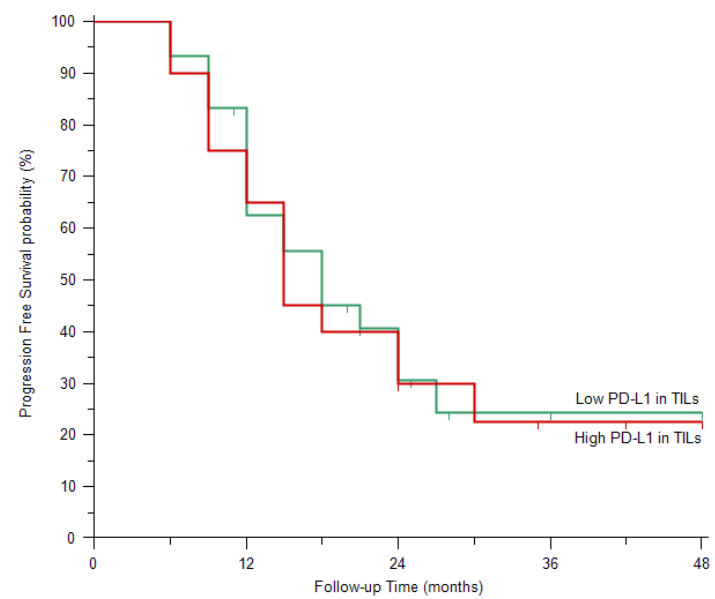

(D)

Figure 2:- Kaplan Meier plot, Left panel: Progression Free Survival, Right panel: Overall Survival; (C \& K) Stratified by FOXP3 in tumor cells, (D \& L) Stratified by PD-L1 in TILs.

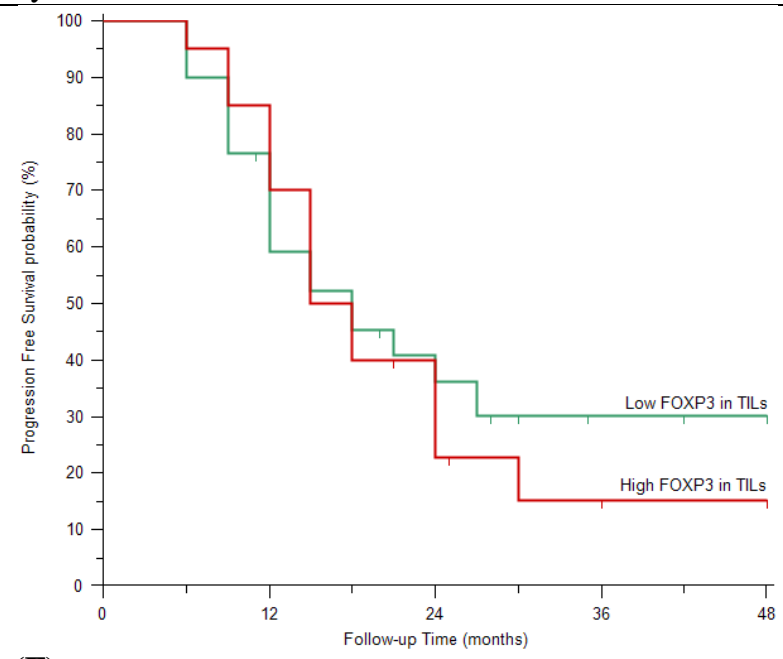

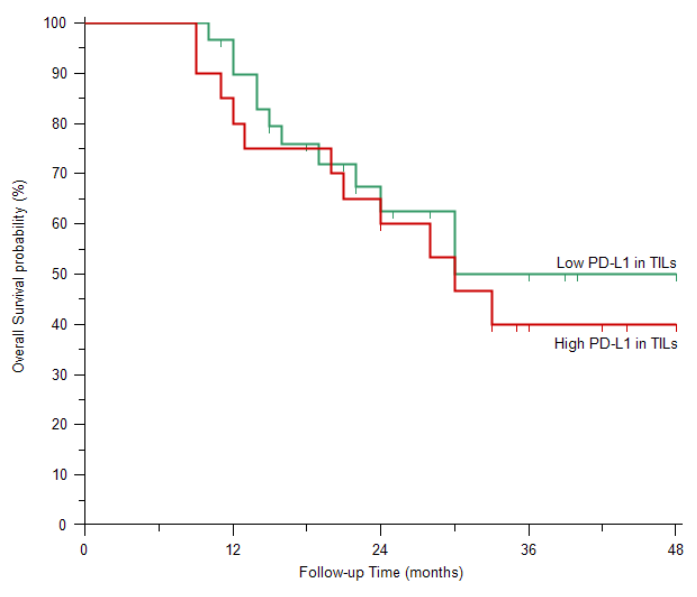

(L)

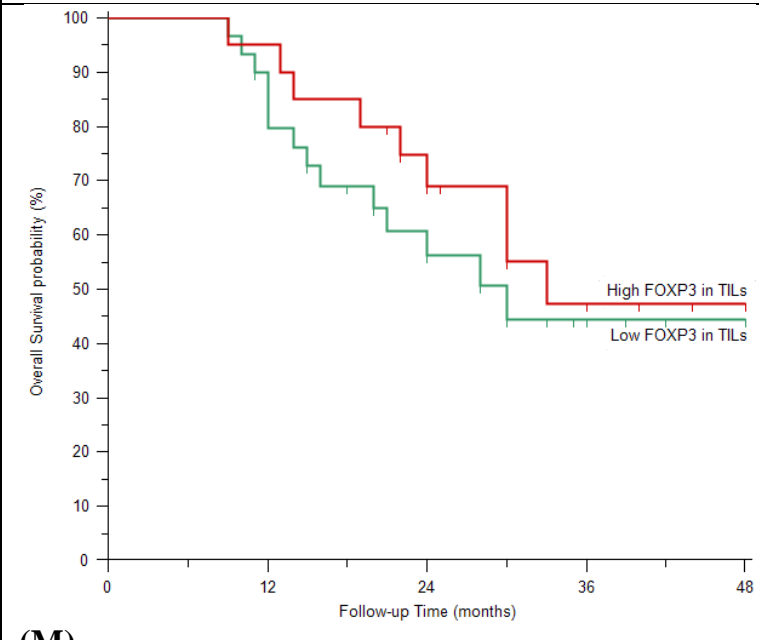

(M) 


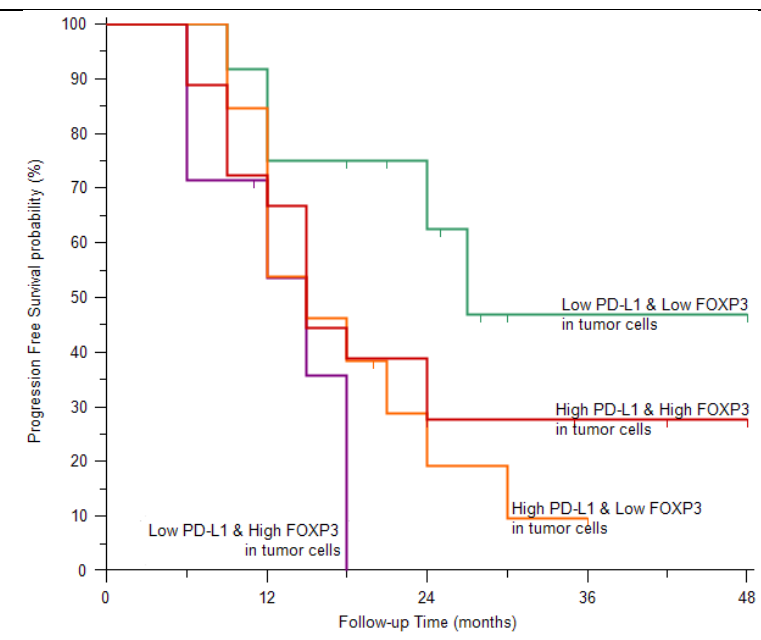

(G)

Figure 3:- Kaplan Meier plot, Left panel: Progression Free Survival, Right panel: Overall Survival; (F \& M) Stratified by FOXP3 in TILs, (G \& N) Stratified by PDL1 \& FOXP3 in tumor cells

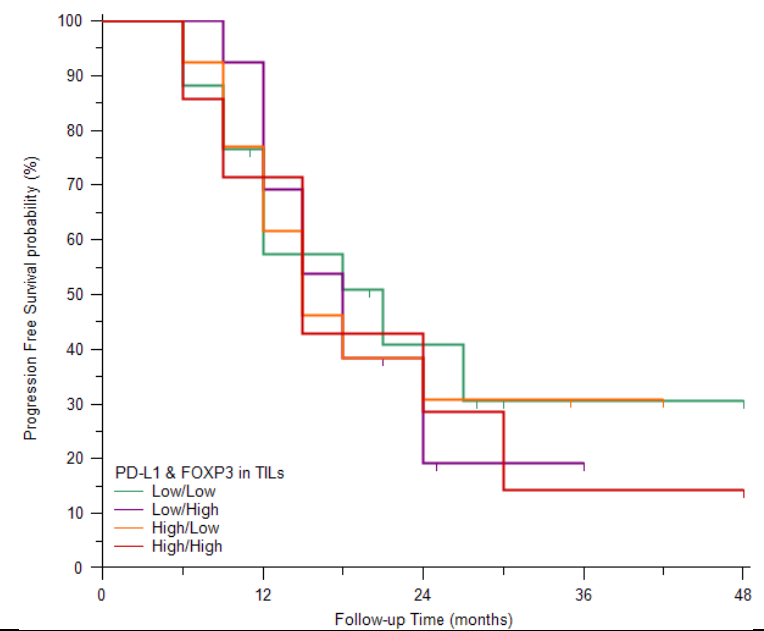

(H)

Figure 4:- Kaplan Meier plot, Left panel: Progression Free Survival, Right panel: Overall Survival; (H \& O) Stratified by PD-L1 \& FOXP3 in TILs.

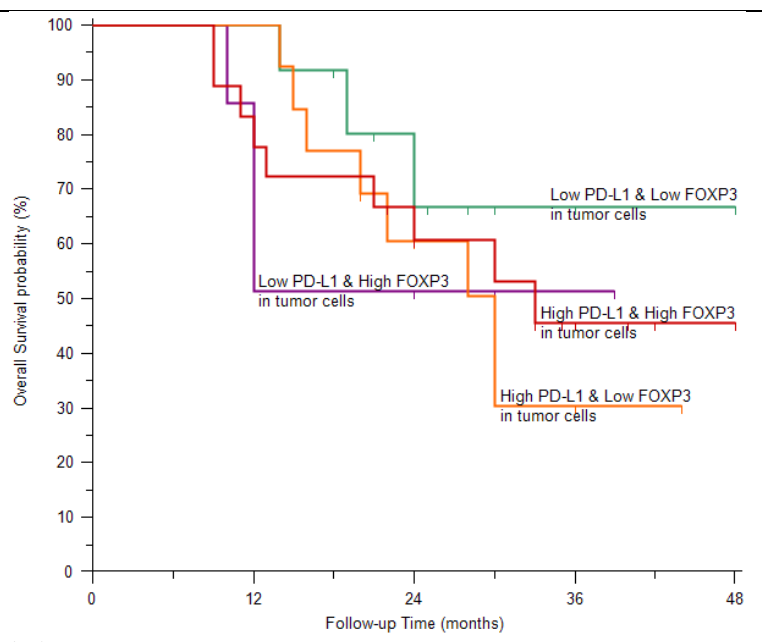

(N)

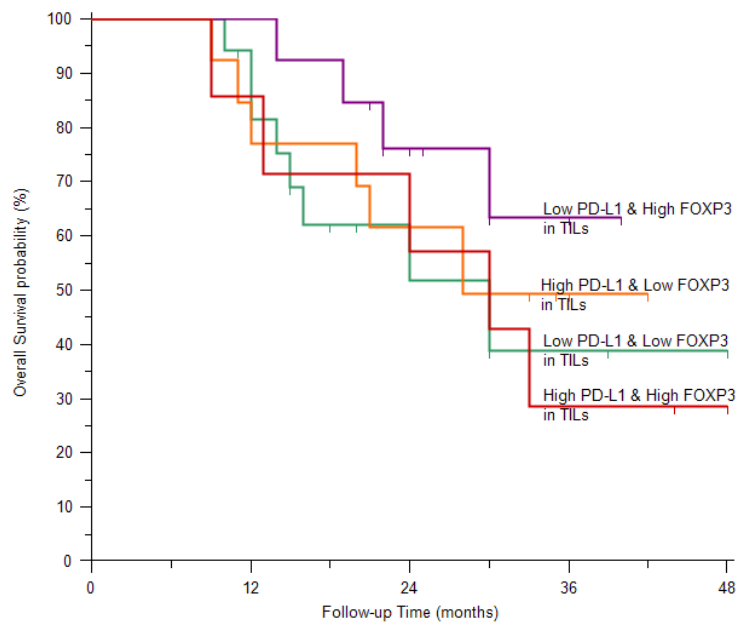

(O) 


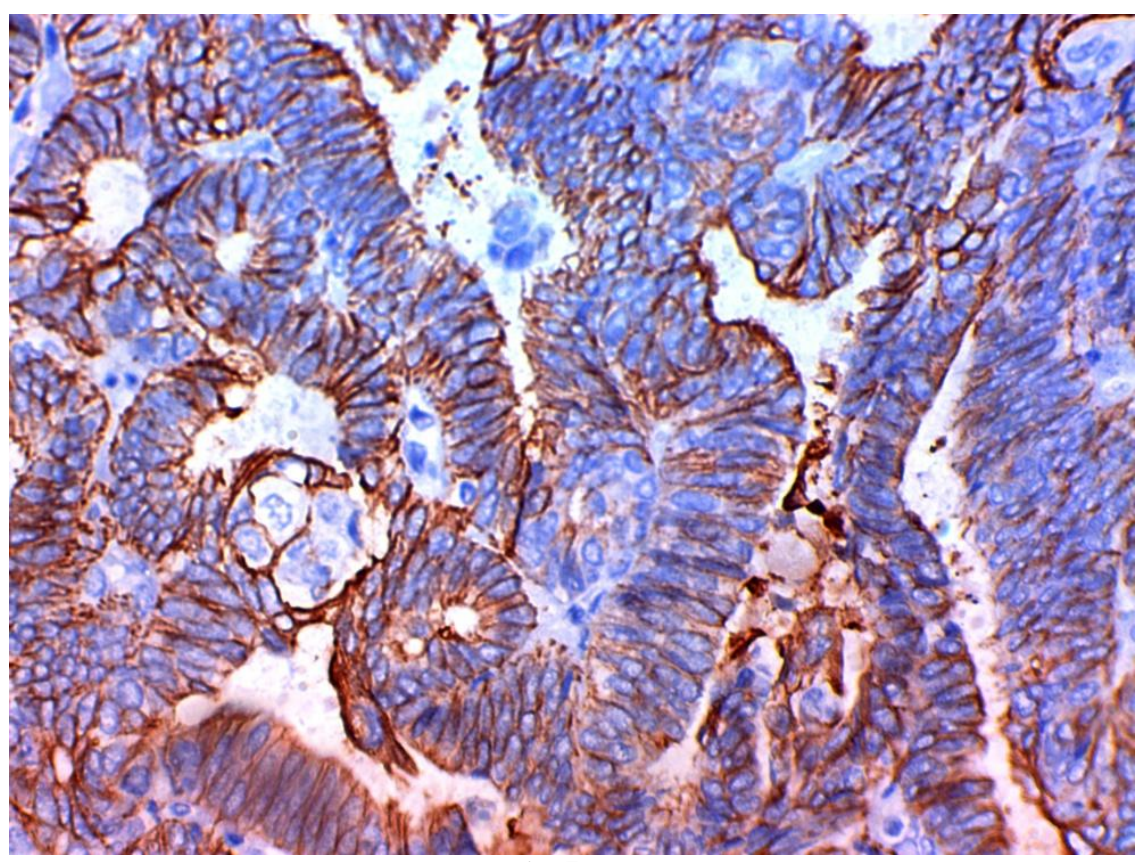

Fig 5:- A

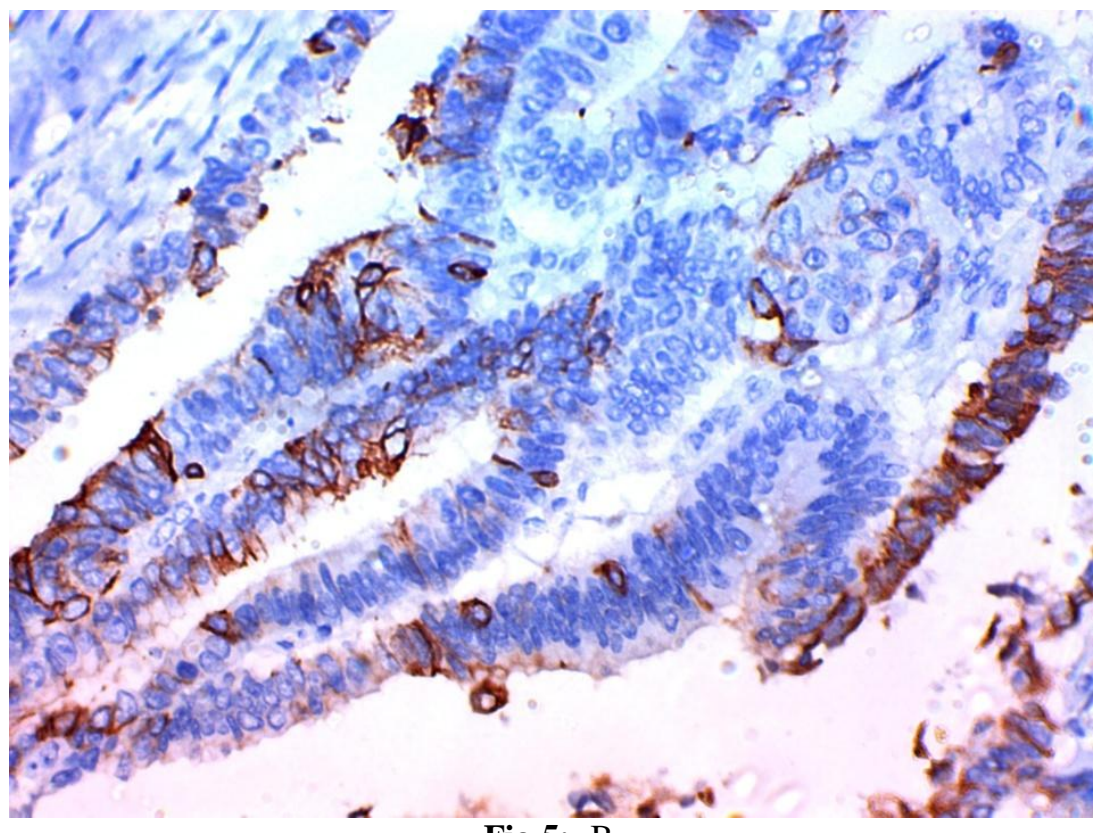

Fig 5:- B 


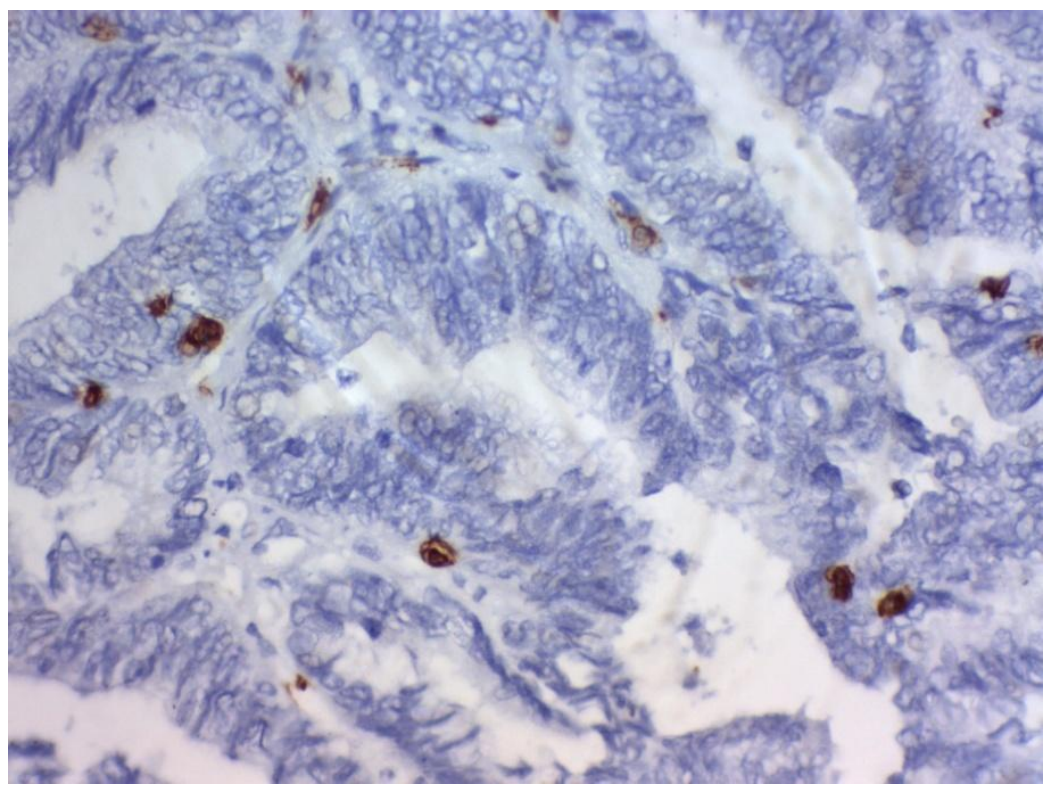

Fig 5:- C

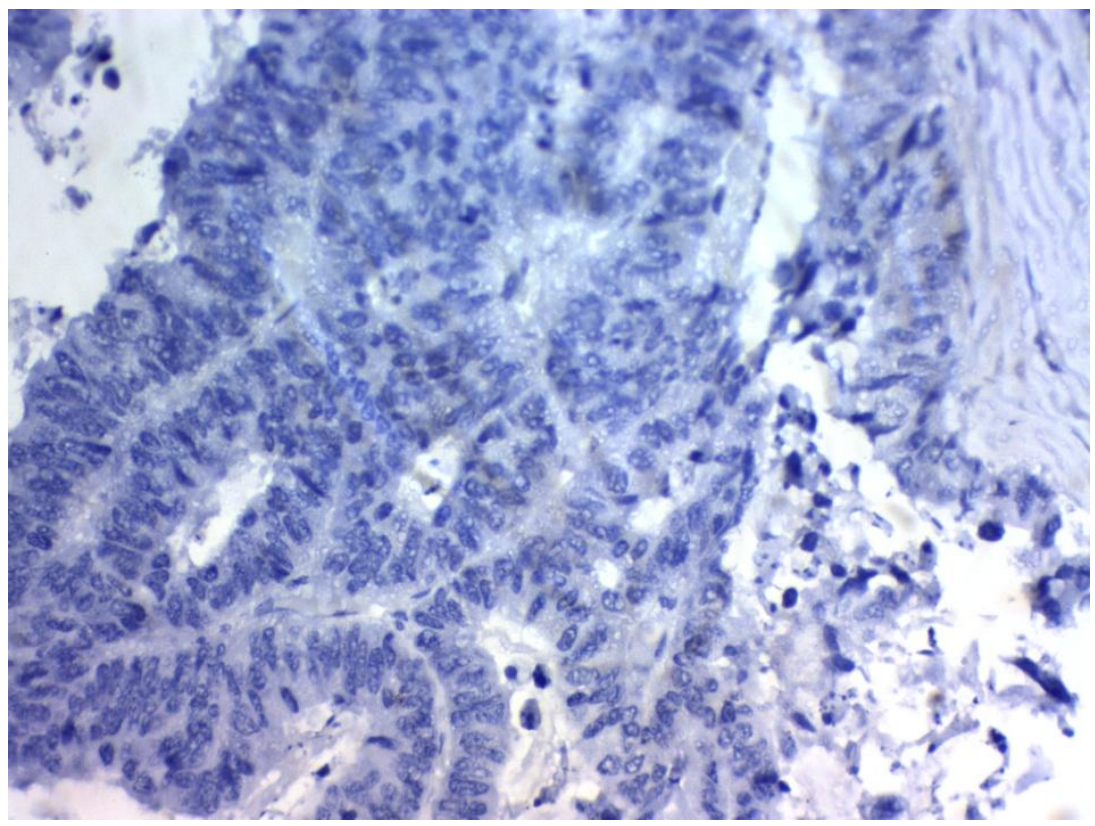

Fig 5:- D

Figure 5:- Immunohistochemical expression of PD-L1 in epithelial ovarian carcinoma cells and tumor infiltrating lymphocytes (TILs) :( A) High expression of PD-L1 in papillary serous cystadenocarcinoma of the ovary high grade, stage IIIx400. (B) Low expression of PD-L1 in papillary serous cystadenocarcinoma of the ovary low grade, stage IIx400. (c) High expression in TILs of papillary serous cystadenocarcinoma of the ovary high grade, stage III x400 (D) Low expression in the TILs of papillary serous cystadenocarcinoma of the ovary low grade, stage IIx400.

Note: High PD-L1 immunohistochemical expression in high grade \& stage ovarian carcinoma and low expression in low grade \&stage ovarian carcinoma: A, B, C\&D the original magnification was $\times 400$ 


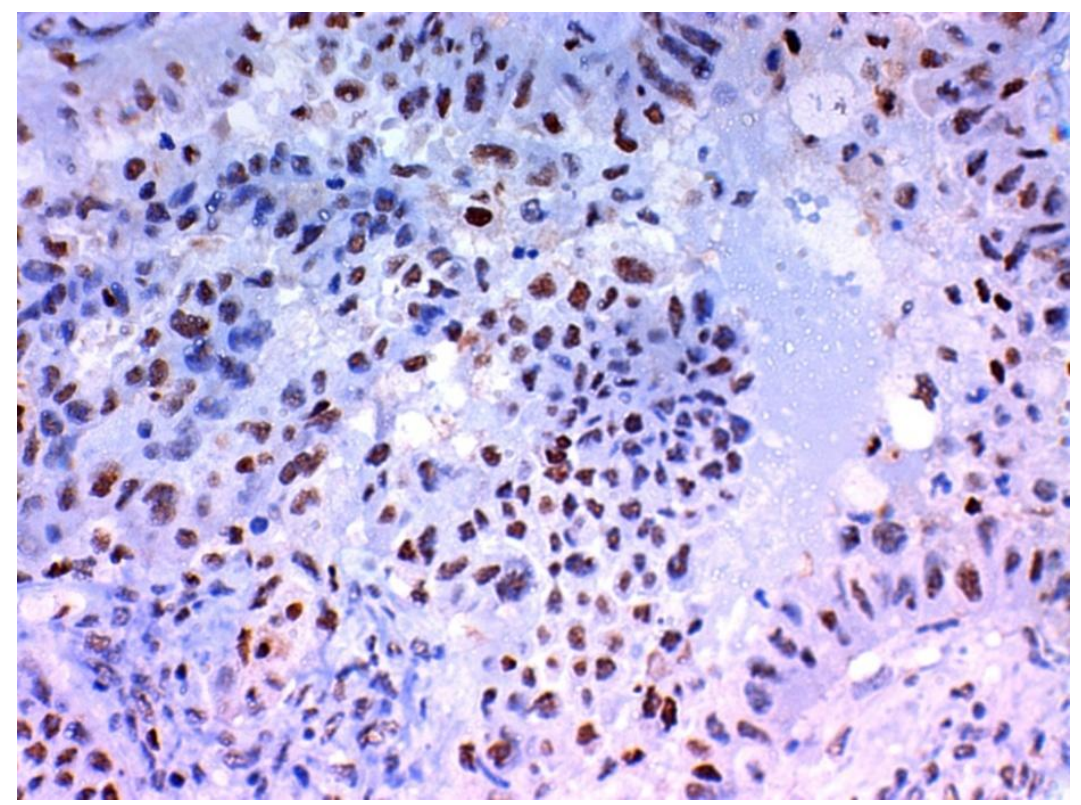

Fig 6:- A

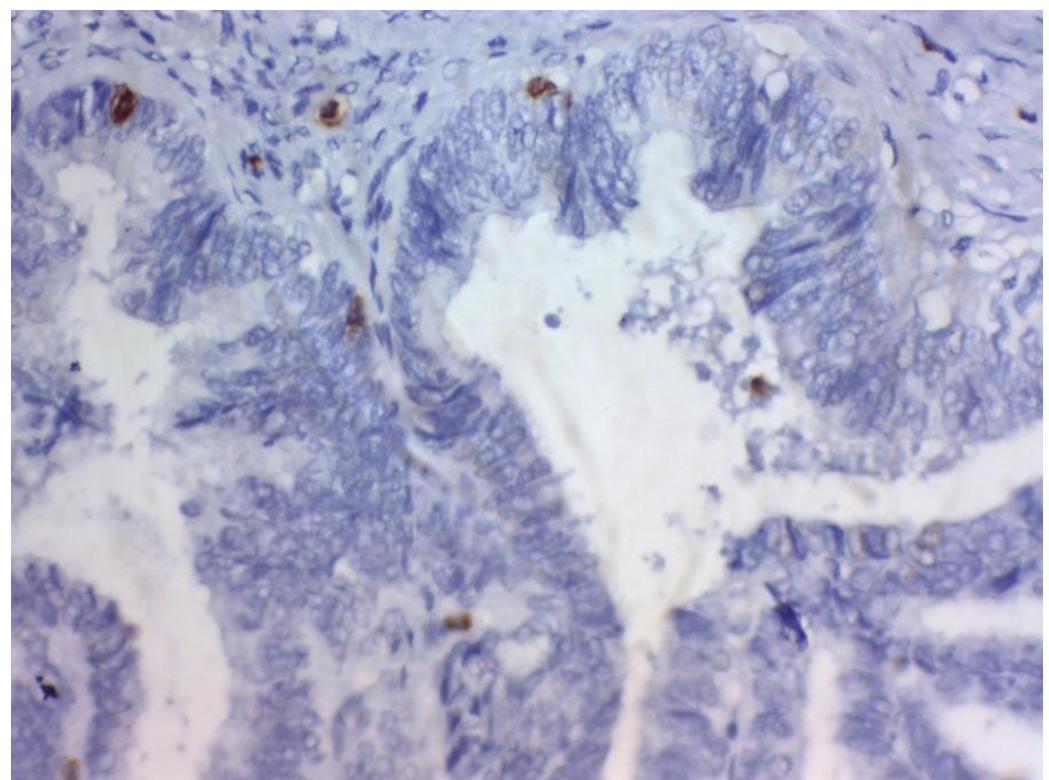

Fig 6:- B

Figure 6:- Immunohistochemical expression of FOXP3 in epithelial ovarian carcinoma cells and tumor infiltrating lymphocytes (TILs) :(A) High expression in tumor cells and TILs in papillary serous cystadenocarcinoma of the ovary high grade, stage IIIx400 . (B) Low expression in the cells and TILs in papillary serous cystadenocarcinoma of the ovary low grade, stage IIBx 400 .

Note:- High FOXP3 expression in high grade \& stage ovarian carcinoma and low expression in low grade \&stage ovarian carcinoma: A\& B the original magnification was $\times 400$

\section{Discussion:-}

The microenvironment of epithelial ovarian cancer (EOC) is heterogeneous and various immune cell populations have been associated positively or negatively with clinical prognosis, including tumor-infiltrating lymphocytes (TILs) (3). In ovarian cancer; TILs express the immune receptor programmed cell death 1 (PD-1), but cancer cells express its ligand PD-L1 (20,16). 
We found that high expression of PD-L1 in tumor cells was significantly positively correlated with histopathologicaltype, high grade, advanced stage of the tumor and high lymph node metastases, type of surgery with presence of residual disease after surgery. High expression of PD-L1 in TILs was significantly positively correlated with grade, stage of the tumor . In addition, there were, in our result ,Fifteen of 22 with residual disease (68.2\%) patients had response to treatment; 11 (50\%) patients had CR whereas 4 (18.2\%) patients had PR Only 7 (31.8\%) patients had no response (SD\&PD) .Overall 35 patients (70\%) had progression and $23(46 \%)$ patients died. We found high response rate, less progression and less mortality in patients with low PD-L1 expression in tumor cells or TILs but with no significant correlation between them with each marker or their combination with FOXP3 . There were high $4 \mathrm{y}$ - DFS and 4y-OS in patients with low PD-L1 expression in tumor cells or TILs but with no significant correlation with each marker. Combined low PD-L1\& FOXP3 expressions in tumor cells were significantly associated with higher progression free survival (PFS) $(\mathrm{p}<0.045)$.

Hamanishi et al., 2007(16) found similar results to ours that over expression of PD-L1 has been associated with poor clinicopathological parameters and poor overall survival in EOC, which meant that there will be a benefit from PD-1/ PD-L1 inhibition in EOC patients. Hamanishi et al., 2015 (21) gave another proof of the therapeutic benefits of the PD-1/ PD-L1 pathway in EOC. Wu et al., 2015 (22) mentioned that tumor expression of PD-L1 was positively correlated with cancer progression and poor prognosis of malignancies of many organs, but full accurate data are not available and are conflicting. This problem might be due to usage of different antibodies clones which had different specificity with variable scoring methods (8).

Similar results proved by Taube, et al., 2014 (23) that PD-L1 was expressed in the cancer microenvironment, mainly in TILs and had the strongest association with response to nivolumab. These results clarified measuring, not only PD-L1 positivity in tumor cell, but also PD-L1 positivity in TILs for immune checkpoint therapy response prediction. Sabatier et al., 2015 (24) proved in his mRNA study results that were different from our results in that high/unregulated PD-L1 expression was associated with better survival, However, Baptista et al , 2016 (25), found that high PD-L1 protein expression was associated with shorter survival which was like our reults.PD-L1 expression in malignant cells is a recent prognostic marker that could prove the antitumor immunity interruption .Previous studies proved that PD-L1 overexpression was an important prognostic factor in malignancies of many organs (26) . PD-L1 overexpression and relations to patient prognosis differ according to cancer type (27).

So, our data revealed that PD-L1 overexpression by EOC cells is a significant prognostic factor and such expression allow better evaluation of host-tumor immunity that allow better treatment of ovarian cancer. Recently, many researches proved that cancers with PD-L1-positive TILs had a high response rates to cancer immunotherapies, proving the role of PD-L1 as a predictive marker of response to anti-PD-1 antibody therapy (28).

Usage of immunotherapy in treatment of cancer is rapidly evolving from therapies that non-specifically stimulate the immune system to more specific and targeted activation of specific components of the immune system with decreased toxicity and increased efficacy of immunotherapy. Therapies that inhibit the interaction between programmed death ligand 1 (PD-L1) and programmed death 1 (PD-1), are generating much excitement , even in malignancies that are not traditionally considered to be immunogenic (29). Anti-PD therapy has become the backbone of cancer immunotherapy and a major modality of cancer treatment. It is important to learn from this successful therapy for better understanding of the immune system and its role in cancer and to improve future therapies (30).

We found that high expression of FOXP3 in tumor cells was significantly positively correlated with poor clinicopathological parameters like younger age of the patients, high grade, distant metastases and advanced stage of the tumor. High expression of FOXP3 in TILs was significantly positively correlated with histopathological type of the tumor only. There were high response rate and less progression in patients with low FOXP3 expression in tumor cells or TILs but the mortality was less in patients with low FOXP3 in tumor cells only , with no significant correlation between them with each marker or their combination with PD-L-1 . The mortality was higher in patients with low FOXP3 in TILs only but without any significance There were high $4 \mathrm{y}$ - DFS in patients with low FOXP3 expression in tumor cells or TILs but with no significant correlation with each marker . However there were low 4y-OS in patients with low FOXP3 expression in tumor cells or TILs but with no significant correlation with each marker. Combined low PD-L1\& FOXP3 expressions in tumor cells were significantly associated with higher progression free survival (PFS) $(\mathrm{p}<0.045)$. 
Our results were in agreed with previous studies in ovarian carcinoma (31).Curiel et al., 2004, (5) who proved that FOXP3 over expression in cancer cells is associated with poor prognosis and decreased survival which could be due to their suppressive effects on anticancer immune responses. Recently ,Foxp3 was found to be not only specifically expressed in Treg cells which were normally arose in the thymus, but also in the malignant cells and its expression is positively correlated to cancer progression and prognosis (32). This relation has been reported in a many metastatic or non-metastatic cancers (11).

There are several studies proved an inverse correlation between FOXP3 expression in Tregs and survival in certain kinds of tumors (33), in contrast to us as we found no significant correlations between FOXP3 expression in tumor cells or TILs and worsened survival rates of the patients like many other studies which indicated that there were no significant correlation between FOXP3+ Tregs and survival $(\mathbf{3 4}, \mathbf{3 5}, \mathbf{3 6})$

So, conflicting data had been reported about the prognostic role of FOXP3+ Tregs infiltration in cancers which may play a negative, positive or non-significant role in cancer patient prognosis and survival(11). The association of FOXP3 positivity and poor prognosis could be explained by that FOXP3+ Tregs cells in ovarian carcinomas express intracellular FOXP3, inhibit host immunity and stimulate cancer growth (18). Also ,Hinz et al 2007(37) added another explanation for that as inhibition of an effector T-cell response allow cancer immune escape. Merlo et al , 2009 (38) found that FOXP3 over expression was associated with decreased overall and metastasis free survival rates but not with local recurrence; so, FOXP3 expression was related to the cancer metastatic ability rather than to a specific immune response suppression .

These data therefore provide direct evidence that human FOXP3 positive Treg cells have an important immunopathological role in human cancer by suppressing endogenous T cell immunity (39). FOXP3 was found to be a novel therapeutic target so vaccines that eradicate FOXP3-expressing cells increase host immunity against cancer (40).the specific mechanism underlying the role of Foxp3 in cancer pathogenesis is uncertain. Foxp3 expressing Tregs can increase the occurrence of metastasis in cancers. Ma et al 2013(41), found that Foxp3 was markedly expressed in the gastric cacinoma cells and activate the apoptosis pathways so induce gastric cancer cells apoptosis and inhibit the cancer progression so predicted a better prognosis $(\mathbf{4 1 , 1 9 )}$ ). Above findings suggest that Foxp3 role in the cancer cells are still conflicting as it may had a tumor suppressor effect to inhibit cancer progression or stimulate cancer growth by inhibiting immunity but the specific mechanism is still uncertain.

In our study, absence of significance between each one of PDL1 in tumor cells and TILs and FOXP3 in tumor cells and TILs with the response, progression and survival may be due to small number of our patients which is a limitation of our study which may limit our statistical power.

\section{Conclusions:-}

EOC is one of the most life-threatening malignancies and immunotherapy may be a promising supplementary treatment for it in the near future. The role of microenvironment cells in EOC remains controversial and may not be informative for survival prediction after resection of the primary tumor. We found that combination of PDL-1 and FOXP-3 expressions in EOC were correlated with poor prognosis but further studies on large number of cases were recommended to prove our results and clarify the possible use of them as therapeutic targets in cancer.

\section{Refrences:-}

1. Konstantinopoulos PA and Matulonis UA (2013):- Current status and evolution of preclinical drug development models of epithelial ovarian cancer. Front Oncol ; 3: 296.

2. Hanahan D and Coussens LM (2012):- Accessories to the crime: Functions of cells recruited to the tumor microenvironment. Cancer Cell 21:309-322.

3. Zhang L, Conejo-Garcia JR, Katsaros D, et al (2003):- Intratumoral $\mathrm{T}$ cells, recurrence, and survival in epithelial ovarian cancer. N Engl J Med 348:203-213.

4. Curiel TJ, Coukos G, Zou L, et al (2004):- Specific recruitment of regulatory T cells in ovarian carcinoma fosters immune privilege and predicts reduced survival. Nat Med 10:942-949

5. Chen J, Jiang CC, Jin L, et al (2016):- Regulation of PD-L1: a novel role of pro-survival signaling in cancer. Ann Oncol ; 27:409-16.

6. Reiss KA, Forde PM, Brahmer JR et al (2014):- Harnessing the power of the immune system via blockade of PD-1 and PD-L1: a promising new anticancer strategy. Immunotherapy; 6:459-75. 
7. Berretta M, Stanzione B, Di Francia R, et al (2015):- The expression of PDL1 APE1 and P53 in hepatocellular carcinoma and its relationship to clinical pathology. Eur Rev Med PharmacolSci ; 19:4207-9.

8. McLaughlin J , Han G , Schalper K A , et al (2015):-Frequent PD-L1 expression in testicular germ cell tumors. Br. J. Cancer , 113, 411-413.

9. Sakaguchi $\mathbf{S}$ (2005):- Naturally arising Foxp3-expressing CD25+CD4+ regulatory $\mathrm{T}$ cells in immunological tolerance to self and non-self. Nat Immunol ; 6: 345-352.

10. Kerdiles YM, Stone EL, BeisnerDR,et al (2010):- Foxo transcription factors control regulatory $\mathrm{T}$ cell development and function. Immunity ; 33: 890-904.

11. Tan B, Anaka M, Deb S, et al (2014):- FOXP3 over-expression inhibits melanoma tumorigenesis via effects on proliferation and apoptosis. Oncotarget ; 5: 264-276.

12. Prat J (2014):- FIGO Committee on Gynecologic Oncology. Staging classification for cancer of the ovary, fallopian tube, and peritoneum. Int J Gynaecol Obstet. 124 (1):1-5.

13. Kurman RJ, Carcangiu ML, Herrington CS, et al (2014):- WHO Classification of Tumours of Female Reproductive Organs. 4th ed.Lyon: International Agency for Research on Cancer. https://shop.iarc.fr/products/who-classification-of-tumours-of-female-reproductive-organs

14. Rustin GJ (2003): Use of CA-125 to assess response to new agents in ovarian cancer trials. J ClinOncol. , 21 (10 Suppl): 187s-193s.

15. Hsu SM, Raine $\mathbf{L}$ and Fanger $\mathbf{H}$ (1981):- Use of avidin-biotin-peroxidase complex (ABC) in immunoperoxidase techniques: a comparison between $\mathrm{ABC}$ and unlabeled antibody (PAP) procedures. $J$ HistochemCytochem ; 29:577-580.

16. Hamanishi J , Mandai M, Iwasaki M, et al (2007):-Programmed cell death 1 ligand 1 and tumorinfiltrating CD8_ T lymphocytes are prognostic factors of human ovarian cancer, (PNAS) ProcNatlAcadSci USA, vol. 104 , no $9,3360-3365$.

17. Darb-Esfahani1 S, Kunze1 C, Kulbe H, et al (2016):-Prognostic impact of programmed cell death-1 (PD-1) and PD-ligand 1 (PD-L1) expression in cancer cells and tumor infiltrating lymphocytes in ovarian high grade serous carcinoma ,Oncotarget. 2016 Jan 12;7(2):1486-99. doi: 10.18632/oncotarget.6429.

18. Luo Q, Zhang S, Wei H, et al (2015):- Roles of Foxp3 in the occurrence and development of cervical. cancer . Int J ClinExpPathol ;8(8):8717-8730

19. Ma1 G, Miao1 Q, Liu Y, et al (2014):-High FoxP3 expression in tumour cells predicts better survival in gastric cancer and its role in tumour microenvironment . British Journal of Cancer, 110, 1552-1560 .

20. matsuzakiJ,GnjaticS,Mhawech-FaucegliaP,et al (2010:-) Tumor-infiltrating NY-ESO-1-specific CD8 + T cells are negatively regulated by LAG-3 and PD-1 in human ovarian cancer. ProcNatlAcadSci U S A;107:7 875-80.

21. Hamanishi J, Mandai M, Ikeda T, et al (2015):- Safety and antitumor activity of anti-PD-1 antibody, nivolumab, in patients with platinum-resistant ovarian cancer. J ClinOncol , 1;33(34):4015-22.

22. Wu P , Wu D , Li L ,et al (2015):- PD-L1 and survival in solid tumors: A meta-analysis. PLoS ONE , 10 (6):, e0131403. doi:10.1371/journal.pone.0131403.

23. Taube J.M , Klein A , Brahmer J.R, et al (2014):- Association of PD-1, PD-1 ligands, and other features of the tumor immune microenvironment with response to anti-PD-1 therapy. Clin. Cancer Res, 20, 5064-5074.

24. Sabatier R, Finetti P, Mamessier E, et al (2015);-. Prognostic and predictive value of PDL1 expression in breast cancer. Oncotarget ;6: 5449-64

25. Baptista MZ, Sarian LO, Derchain SF, et al(2016):- Prognostic significance of PD-L1 and PD-L2 in breast cancer. Hum Pathol ;47:78-84.

26. Thompson RH, Kuntz SM, Leibovich BC, et al (2006) :-Tumor B7-H1 is associated with poor prognosis in renal cell carcinoma patients with long-term follow-up, Cancer Res 66 (7):3381- 3385.

27. Konishi J, Yamazaki K, Azuma M, et al(2004):-B7-H1 Expression on Non-Small Cell Lung Cancer Cells and Its Relationship with Tumor-Infiltrating Lymphocytes and Their PD-1 ExpressionClin Cancer Res 10:50945100 .

28. Herbst RS, Soria JC, Kowanetz M, et al (2014):- Predictive correlates of response to the anti-PD-L1 antibody MPDL3280A in cancer patients. Nature ; 515(7528):563-7.

29. Swaika A, Hammond W, JosephR, et al (2015):-Current state of anti-PD-L1 and anti-PD-1 agents in cancer therapy' Molecular immunology,vol 67.issue 2,p 4-17.

30. Chen L and Han X (2015):-Anti-PD-1/PD-L1 therapy of human cancer: past, present, and future . Journal of clinical investigation ;125(9):3384-3391.

31. Leffers N, Gooden MJ, de Jong RA, et al (2009): Prognostic significance of tumor-infiltrating T-lymphocytes in primary and metastatic lesions of advanced stage ovarian cancer. Cancer Immunol Immunother;58(3):449-59 
32. Karanikas V, Speletas M, Zamanakou M, et al (2008):- Foxp3 expression in human cancer cells. J Transl Med ; 6: 19.

33. Ladoire S, Martin F and Ghiringhelli (2011):-Prognostic role of FOXP3+ regulatory T cells infiltrating humancarcinomas: the paradox of colorectal cancerCancerImmunolImmunother , 60:909-918

34. Fu J, Xu D, Liu Z,et al (2007):- Increased regulatory T cells correlate with CD8 T-cell impairment and poor survival in hepatocellular carcinoma patients. Gastroenterology ; 132: 2328-2339.

35. Grabenbauer GG, Lahmer G, Distel L, et al (2006) :-Tumor-inWltrating cytotoxic T cells but not regulatory $\mathrm{T}$ cells predict outcome in anal squamous cell carcinoma. Clin Cancer Res 12:3355-3360

36. Loddenkemper C, Schernus M, Noutsias M, et al (2006):- In situ analysis of FOXP3+ regulatory T cells in human colorectal cancer. J Transl Med 4:52

37. Hinz S, Pagerols-Raluy L, Oberg HH, et al (2007):- Foxp3 expression in pancreatic carcinoma cells as a novel mechanism of immune evasion in cancer. Cancer Res 67:8344-8350.

38. Merlo A, Casalini P, Carcangiu ML, et al (2009):- FOXP3 expression and overall survival in breast cancer. J ClinOncol ,27:1746-1752.

39. Hori S, Nomura T, Sakaguchi S, et al (2003):- Control of regulatory T cell development by the transcription factor Foxp3. Science 299:1057-1061.

40. Nair S, Boczkowski D, Fassnacht M, et al (2007):- Vaccination against the forkhead family transcription factor Foxp3 enhances tumor immunity. Cancer Res 67:371- 380.

41. Ma GF, Chen SY, Sun ZR, et al (2013):-FoxP3 inhibits proliferation and induces apoptosis of gastric cancer cells by activating the apoptotic signaling pathway. BiochemBiophys Res Commun ; 430: 804-809. 